\title{
A Toolkit for Measuring Sprawl
}

\author{
Paul M. Torrens
}

Received: 31 May 2007 / Accepted: 14 January 2008 /

Published online: 15 March 2008

(C) Paul M. Torrens 2008

\begin{abstract}
Debate regarding suburban sprawl in urban studies is contentious. It is fair to say that the phenomenon is not fully understood to satisfaction in the academic, policy, or planning communities and there are a host of reasons why this may be the case. Characterization of sprawl in the literature is often narrative and subjective. Measurement is piecemeal and largely data-driven. Existing studies yield contrary results for the same cities in many cases. The partial appreciation for the intricacies of sprawl is problematic. In practice, city planning agencies and citizen advocacy groups are scrambling to suggest and develop "smart growth" strategies to curb sprawl, without a strong empirical basis for measuring the phenomenon. Yet, sprawl is extremely popular with consumers. In this paper, we develop an innovative approach to diagnosing sprawl, looking across the full range of its characteristic attributes in a comprehensive fashion that is robust to some well-known challenges. This proves to be very useful in sweeping the parameter space of the phenomenon, enabling the visualization and valuation of sprawl surfaces across attributes, allowing us to check the pulse of a developing city. We apply the work to Austin, TX, a controversial exemplar of American sprawl, with the surprising result that sprawl and "smart growth" are found to co-exist and co-evolve. This raises questions about relationships between the two, with consequences for planning and public policy.
\end{abstract}

Keywords Suburban sprawl - Spatial analysis · Urban growth · Smart growth · Growth management - Geographic information science ·

Geographic Information Systems · Planning support systems · Urban analysis

P. M. Torrens $(\bowtie)$

School of Geographical Sciences, Arizona State University, Tempe, AZ 85287, USA

e-mail: torrens@geosimulation.com 


\section{Introduction}

Sprawl is surrounded by controversy. The phenomenon is abhorred by many and is the bane of city planning agencies trying to curb its spread. Sprawl is obviously popular, however, and there is little doubt that lots of people want to live in sprawling suburbs, whether policy-makers consider it prudent for them to do so or not. Discord is also present in our understanding of the phenomenon. Characterization of sprawl is often descriptive with strong differences of opinion as to how sprawl manifests on the ground. Difficulties in translating these textual descriptions into practice present a formidable barrier to evaluating their efficacy as exemplars. Some excellent work has already been undertaken to measure sprawl. Nevertheless, contradictory results are often reported for the same cities when examination of sprawl is quantitative. This is a by-product of sprawl's multi-attribute nature and challenges in measuring the phenomenon, with the result that "smart growth" measures to target sprawl lack the strongest empirical foundation and potential costs and benefits are difficult to gauge.

The literature characterizing sprawl is voluminous. Sprawl is often defined in cost terms (Benfield et al. 1999; Burchell et al. 1998; James Duncan and Associates et al. 1989; Real Estate Research Corporation 1974). Definitions based on benefits are comparatively rare (Bae and Richardson 1994; Gordon and Richardson 1997a, b). Some key distinguishing features do reappear in the literature, however: growth; social and aesthetic attributes; decentralization; accessibility; density characteristics; fragmentation; loss of open space; and dynamics. These attributes serve as the subject matter for our analysis. Each of the characteristics listed is important in explaining sprawl and features as a recurring theme in the literature, although there is sometimes debate as the roles that they play in forming sprawl, as we will explain (diversity in the characterization of sprawl in urban studies literature is illustrated in Table 1).

North American cities are, for the most part, continuing to grow in absolute size and American population is still urbanizing. These trends have been catalyzed by a concurrent drop in average household sizes and jump in the number of housing units. Urban growth has to go somewhere. Cities must expand or fill-in to entertain growth and sprawl is one such accommodation (Burchell et al. 1998; Galster et al. 2001).

Social characteristics are also associated with sprawl. White flight is often implied in the literature (Audirac et al. 1990), with suburban life juxtaposed against perceived ills of the central city. There is much debate surrounding this topic, however (Farley and Frey 1994; Galster 1991).

Aesthetic preferences often flavor characterization of sprawl. Sprawl is widely met with disapproval and distaste on the grounds of design and morphology (Calthorpe et al. 2001; Duany et al. 2000). These complaints often relate to ribbon sprawl (Burchell et al. 1998; Hasse and Lathrop 2003a), dominance of commercial land-use and parking along roads. Exit-parasitic retail development is an associated component: the clustering of hotels, gas stations, fast food restaurants, and so forth close to highway exit ramps.

Assumption of decentralization from a central core to the urban periphery is often fundamental to sprawl's characterization (Ewing et al. 2002; Galster et al. 2001). Sprawl is commonly linked to economic suburbanization, with an assertion that jobs 
Table 1 The varying characterization of sprawl in urban studies literature

\begin{tabular}{|c|c|c|c|c|c|c|c|c|c|c|}
\hline & Growth & Social & Aesthetic & Decentralization & Accessibility & Density & Open space & Dynamics & Costs & Benefits \\
\hline \multicolumn{11}{|l|}{ Audirac, et al (1990) } \\
\hline \multicolumn{11}{|c|}{ Bae \& Richardson (1994) } \\
\hline \multicolumn{11}{|l|}{ Benfield et al (1999) } \\
\hline \multicolumn{11}{|l|}{ Burchell, et al (1998) } \\
\hline \multicolumn{11}{|c|}{ Calthorpe, et al (2001) } \\
\hline \multicolumn{11}{|l|}{ Clapham Jr. (2003) } \\
\hline \multicolumn{11}{|l|}{ Duany, et al (2000) } \\
\hline \multicolumn{11}{|c|}{ El Nasser \& Overburg (2001) } \\
\hline \multicolumn{11}{|l|}{ Ewing, (1997) } \\
\hline \multicolumn{11}{|l|}{ Ewing, et al (2002) } \\
\hline \multicolumn{11}{|l|}{ Farley \& Frey (1994) } \\
\hline \multicolumn{11}{|l|}{ Galster (1991) } \\
\hline \multicolumn{11}{|l|}{ Galster, et al (2001) } \\
\hline \multicolumn{11}{|c|}{ Gordan \& Richardson (1997a) } \\
\hline \multicolumn{11}{|c|}{ Gordon \& Richardson (1997b) } \\
\hline \multicolumn{11}{|c|}{ Hasse \& Lathrop (2003a) } \\
\hline \multicolumn{11}{|c|}{ Hasse \& Lathrop (2003b) } \\
\hline \multicolumn{11}{|l|}{ Hasse (2004) } \\
\hline \multicolumn{11}{|l|}{ HUD (1999) } \\
\hline \multicolumn{11}{|c|}{ James Duncan \& Associates et al (1989) } \\
\hline \multicolumn{11}{|l|}{ Lang (2003) } \\
\hline \multicolumn{11}{|l|}{ Ledermann (1967) } \\
\hline \multicolumn{11}{|l|}{ Lessinger (1962) } \\
\hline \multicolumn{11}{|l|}{ Malpezzi (1999) } \\
\hline \multicolumn{11}{|l|}{ OTA (1995) } \\
\hline \multicolumn{11}{|l|}{ Peiser (1989) } \\
\hline \multicolumn{11}{|l|}{ Pendall (1999) } \\
\hline \multicolumn{11}{|c|}{ Real Estate Research Corporation (1973) } \\
\hline Sierra Club (1998) & & & & & & & & & & \\
\hline Sudhira et al (2003) & & & & & & & & & & \\
\hline
\end{tabular}

and development follow population to the fringe and that businesses chase perceived discounts in development costs and greater access to highways there. Indeed, job creation has traditionally been more active, and office space more available, in suburban areas in the USA (OTA 1995).

Accessibility is a related issue (Ewing 1997; Sultana and Weber 2007). Suburban households in the US drive more per year, on average, than those in central cities (HUD 1999). Sprawl's accessibility characteristics are among the most frequentlymeasured. The Sierra Club, for example, used time wasted in traffic as one measure of sprawl (1998). Other examples include measures of accessibility for given urban designs (Ewing et al. 2002); access to urban resources (Ewing et al. 2002; Hasse 2004); and opportunity diversity in land-use mix (Burchell et al. 1998; Ewing et al. 2002; Hasse and Lathrop 2003a; Malpezzi 1999).

Density characteristics are chief among sprawl's attributes. Sprawl is commonly regarded as a low density phenomenon, although there is debate as to whether this characterization is appropriate (Ewing 1997; Gordon and Richardson 1997a, b; Lang 2003; Peiser 1989). Low density is considered to be problematic because buildings that need to be supplied with services are further away from central service nodes and from each other than might be expected in denser developments. Lower densities also contribute to accessibility problems, as opportunities take more time to walk and drive to than in densely-settled areas. Impermeable surface grows as development footprints grow, with associated problems of runoff-related pollution and urban heat islands (Alberti 1999). There are benefits, however, in dispersing air pollutants (Bae and Richardson 1994). It remains unclear as to which variables should be used to measure density: housing units (Real Estate Research Corporation 1974), development (Burchell et al. 1998), population (El Nasser and Overberg 2001; Ledermann 1967), employment, or combinations of these attributes (Galster et 
al. 2001). There is also disagreement regarding the scale of observation that should be used: all land (gross density) (Ewing et al. 2002), urban area (Ewing et al. 2002; Pendall 1999), developable area (Galster et al. 2001), urban fringe (Burchell et al. 1998; Lang 2003), or smaller subsets, say all area save that in which people could not possibly reside (net density).

Scattering is another important attribute that is often used to characterize sprawl as tracts of developed land that sit in isolation from other undeveloped tracts (Lessinger 1962). A wide variety of techniques are employed in measuring sprawl scatter, including design measures over urban grids (Galster et al. 2001) and distance from previously-urbanized settlements (Hasse and Lathrop 2003a). Differentiating scattered sprawl from economically-efficient discontinuous development can be difficult, however (Ewing 1994, 1997).

Erosion of open space under sprawl is another popular characteristic of the phenomenon. Open space has featured in measurement of sprawl, generally (Sierra Club 1998); however, consideration of land cover relates, for the most part, to remote sensing analyses of sprawl (Burchfield et al. 2006; Clapham 2003; Hasse and Lathrop 2003b; Sudhira et al. 2003). Ribbon sprawl may restrict access to nearby open space. Leapfrogging development leaves open space but it is generally held in private hands and it is often worth too much money to be used as farmland (Ewing 1994).

Dynamics are also important to sprawl characterization (Lopez and Hynes 2003). Today's sprawl could turn into compact and sustainable development in later years as the pace of urban extension drives developers to fill-in previously undeveloped sites (Peiser 1989). Understanding of sprawl dynamics requires examination of change in the space-time distribution of each of the characteristics discussed thus far. Commonly, this is achieved by proxy, tracking characteristics by temporal crosssection across several cities (El Nasser and Overberg 2001; Lang 2003; Pendall 1999).

Significant progress has been made in quantifying sprawl, but challenges remain. Methodologies are highly variable and are often data-driven rather than having a foundation in theory or practice. Different lenses are used to study sprawl. The bulk of existing studies focus on one or two characteristics for a single city or across a number of cities. Measurement is often focused on the city as a unit. Some studies have treated cities on an intra-urban basis, but work has rarely been done at multiple scales. A distinction between core and periphery is seldom made. Moreover, metrics designed to work at one scale do not always function at another. Sprawl is a dynamic phenomenon, yet work on sprawl often focuses on a single temporal snapshot or disjointed snapshots, rather than following longitudinally in synchrony with urban evolution. The methodology most commonly employed in analysis relies heavily on descriptive and multivariate statistics that are prone to unreliable results owing to spatial autocorrelation (Berry 1993; Fotheringham et al. 2004; Moran 1950). Use of geospatial metrics to avoid spatial autocorrelation problems (usually a fatal roadblock when encountered in analysis) is exceptional when measuring sprawl. Moreover, many of the studies - and the dataware at their foundation - suffer from problems of ecological fallacy and modifiable areal units (Openshaw 1983), due to an over-reliance on Census data that are reported at aggregate spatio-temporal units. On an operational level, measurement of sprawl is generally tabular in form, and 型 Springer 
efforts to map and visualize the problem-space of the phenomenon have been few and far between.

\section{Methods}

We have adopted a novel approach to measuring sprawl, looking across the problem(and benefit-) space of the phenomenon. We demonstrate its application to a contentious exemplar of sprawl and prove the usefulness of our approach in circumnavigating some methodological difficulties. We have declared some groundrules for ourselves in developing our methodology. Measurements should translate descriptive characteristics to quantitative form. The methodology should be broad enough to accommodate all of the characteristics of the phenomenon that can be measured. Analysis should focus at micro-, meso-, and macro-scales and should operate over net and gross land. The analysis should examine sprawl at city-scale and at intra-urban levels. Metrics should treat sprawl's geography explicitly: spatial autocorrelation should be avoided in statistical analysis. The methodology should also track space-time dynamics. Where possible, metrics should be mapped, such that characteristic layers of sprawl can be presented and compared visually. The geography of our analysis is multi-scale in design. We examine sprawl at the level of the metropolitan area as well as locally, down to the level of land parcels. Although inter-urban comparison is not focused on in this paper, the methodology should be sufficient to be generalized to other cities. We have devised a series of 42 measures of sprawl (Table 2), which are tracked longitudinally across a 10-year period and broadly cover each of the characteristics listed in Table 1.

Our analysis is focused on one city across the complete range of sprawl characteristics we have identified in "Introduction". Our study area is Austin, TX, the fifth most rapidly-growing Metropolitan Area in population in the USA and a

Table 2 Measured attributes of sprawl

\begin{tabular}{|c|c|c|}
\hline Characteristic & Attributes measured & $\begin{array}{l}\text { Number of } \\
\text { metrics }\end{array}$ \\
\hline Urban growth & $\begin{array}{l}\text { Urban footprint of the city; developable land; residential footprint of the } \\
\text { city; low-density residential footprint of the city; total number of urban } \\
\text { patches; urban patches by activity ( } 12 \text { land-uses) }\end{array}$ & 18 \\
\hline Density & $\begin{array}{l}\text { Gross population density surface; population density surface considered } \\
\text { over developable land; population density profile as a function of } \\
\text { accessibility to the CBD (considered over all land and developable land); } \\
\text { family density profile as a function of accessibility to the CBD; density } \\
\text { gradient by OLS regression; density gradient by spatial regression }\end{array}$ & 7 \\
\hline Social & Owner-occupation profile; renter-occupation profile & 2 \\
\hline Activity-space & Diversity index; evenness index & 2 \\
\hline Fragmentation & Fractal dimension; contagion; interspersion and juxtaposition index & 3 \\
\hline Decentralization & $\begin{array}{l}\text { Gross global spatial autocorrelation; global spatial autocorrelation over } \\
\text { developable land; local spatial autocorrelation over all land; local spatial } \\
\text { autocorrelation over developable land; spatial hotspots and coolspots }\end{array}$ & 5 \\
\hline Accessibility & $\begin{array}{l}\text { Accessibility to the CBD; to major employers; to schools; to other } \\
\text { educational opportunities; to locally-unwanted land-uses }\end{array}$ & 5 \\
\hline
\end{tabular}


contentious archetype of sprawl. Its population swelled by 48\% from 1990 to 2000 , a rate that is higher than Phoenix, Atlanta, Denver, Dallas-Fort Worth, and Salt Lake City, cities that feature in the literature as popular examples of sprawl run amok. The Sierra Club (1998) named Austin among the most sprawling medium-size metropolitan areas. Ewing et al. (2002) ranked Austin 25th out of 83 cities, higher than Las Vegas (36th), Los Angeles (39th), Houston (52nd), and Atlanta (80th), in terms of its increase in sprawl. Lang (2003) ranked Austin as the fourth most low-density city out of the fifty cities that he studied. There is, however, dissension as to whether Austin sprawls or not. The city scored below average for connectivity and density on Ewing et al.'s (2002) four-score system. Fulton and colleagues rank the city as the fifth highest-density city in their analysis (Fulton et al. 2001).

Austin is also an interesting case study because the city has put a series of smart growth initiatives in place to combat unsustainable population growth (Sui et al. 2004). The city has also initiated programs designed to improve urban quality-oflife, focusing on neighborhoods, the environment, and city-wide accessibility as a panacea for sprawl.

\section{Growth Characteristics}

Growth characteristics are gauged globally in our analysis by monitoring the spatial footprint of urban Austin, residential Austin, and developable Austin (Table 3). These distinctions feature in our analysis of other characteristics. The data sources for these (and subsequently-described) analyses are parcel records (historical, house and yard, as well as building and car park footprints, and land-use and some sociodemographic data) and Census records (historical, social, economic, and demographic data). We also measure urbanization locally using patches (Forman 1995), which are discrete and cohesive spatial and temporal areas of homogenous activity. Patches are calculated from land parcel footprint and land-use data (from Table 3), using moving filters that evaluate cohesion based on local adjacency, with cohesion considered at a resolution of $100 \mathrm{~m}$.

We measure density using profiles, gradients, and surfaces at global and local scales, over net and gross land, across land-uses, and using a variety of variables.

Table 3 The land-use aggregations used in this study

\begin{tabular}{|c|c|c|c|c|}
\hline Land-use & Residential & Sprawl residential & Urban & Developable land \\
\hline Civic & & & $\sqrt{ }$ & \\
\hline Commercial & & & $\sqrt{ }$ & $\sqrt{ }$ \\
\hline $\begin{array}{l}\text { Large lot single-family } \\
\text { Mining }\end{array}$ & $\sqrt{ }$ & $\sqrt{ }$ & $\sqrt{ }$ & $\sqrt{ }$ \\
\hline Mobile homes & $\sqrt{ }$ & & $\sqrt{ }$ & $\sqrt{ }$ \\
\hline Multi-family & $\sqrt{ }$ & & $\sqrt{ }$ & $\sqrt{ }$ \\
\hline Office & & & $\sqrt{ }$ & $\sqrt{ }$ \\
\hline Open Space & & & & \\
\hline Single-family & $\sqrt{ }$ & $\sqrt{ }$ & $\sqrt{ }$ & $\sqrt{ }$ \\
\hline Transportation & & & $\sqrt{ }$ & $\sqrt{ }$ \\
\hline Undeveloped/rural & & & & $\sqrt{ }$ \\
\hline Utilities & & & $\sqrt{ }$ & $\sqrt{ }$ \\
\hline Water & & & & \\
\hline
\end{tabular}


Density profiles usually convey the density cross-section of a city from one point to another. Hundreds of thousands of points should really be considered in a city, however. We divide the city into half-mile concentric bands based on (straight-line and road network) distance from the CBD. Density of various land-uses and characteristics is then summed for that band and graphed against distance to produce a profile that represents all origin points in the city within these bands relative the CBD. Density profiles yield a visual indicator of density-growth or density-decline.

\section{Density Characteristics}

We use density gradients to determine profile rates of (spatial and temporal) change. Gradient values are commonly calculated by regressing density against distance by Ordinary Least-Squares (OLS) means (Mills and Tan 1980). The gradient is the elasticity in the relationship between the two. OLS measures are problematic metrics of sprawl, however. Density gradients attenuate or grow with distance by their very nature; they inherently succumb to spatial autocorrelation, thereby invalidating OLS regression results (Berry 1993). We employ a spatially-adjusted regression model to get around these problems (Fotheringham et al. 2000), which includes a vector of adjacent means (a spatial lag) of the dependent variable as an extra independent variable in the analysis. The regression model is formulated as follows.

$$
W \cdot D=a+\rho d+e, \text { where } e_{i}=\rho \sum_{j=1}^{n} w_{i j} e_{i}+u_{i}
$$

Where $D$ is density, $d$ is distance, and $W$ is a vector of adjacencies $w_{i j}$ between spatial units $i$ and $j . w_{i j}=\frac{1}{a}$ if parcels $i$ and $j$ are adjacent ( $a$ is the number of parcels that are contiguous with $i$ ) and $w_{i j}=0$ if they are not. $w_{i j}=0 \forall i$; spatial units are not adjacent to themselves. This adjusted regression yields an elasticity parameter $(\rho)$ that represents the relationship between $W \cdot D$ and $d$, given the equation. Errors $e_{i}$ for an individual spatial unit $i$ contain the remaining error $\left(u_{i}\right)$ after the correction among residuals has been accounted for. Using this adjusted error, we can generate adjusted dependent $\left(y_{i}^{*}\right)$ and independent variables $\left(x_{i}^{*}\right)$ as ingredients for a second standard regression that yields statistically-reliable estimates and includes spatial autocorrelation in its explanatory power. $y_{i}^{*}$ and $x_{i}^{*}$ are calculated as follows.

$$
y_{i}^{*}=y_{i}-\rho \sum_{j=1}^{n} w_{i j} y_{i} \text { and } x_{i}^{*}=x_{i}-\rho \sum_{j=1}^{n} w_{i j} x_{i}
$$

Gradient and profile measures of density are useful in capturing density metrics over the city in a one-dimensional context. It is also useful to consider density in two dimensions, as an activity surface. To this end, we also map density in two- and threedimensions in our analysis, to study the clustering (or not) of density over space.

\section{Land-use and Activity Characteristics}

Diversity in activities is captured using Shannon's Diversity Index, a modified version of Shannon's communication entropy (Shannon 1948) that measures the 
amount of activity "information" on a per-patch basis. The index (SHDI) reaches a value of zero when diversity is absent and increases as diversity grows. The index is calculated as follows.

$$
\mathrm{SHDI}=-\sum_{i=1}^{m}\left(P_{i} \ln P_{i}\right), \text { where SHDI } \geq 0
$$

Where, $m$ is the number of land-uses $(i)$ present in the study area. $P_{i}$ is the proportion of the study area that is occupied by land-use $i$.

We use Simpson's Evenness Index to gauge activity evenness (Krummel et al. 1981). The value of the Index (SIEI) nears zero when distribution of area among different activities grows uneven (is dominated by one activity) and reaches zero when the landscape contains only a single patch of activity. The value reaches one when the distribution of area is even, i.e. when proportional abundances for land-use are the same. The index is formulated as follows, with the included parameters as defined already.

$$
\mathrm{SIEI}=\frac{1-\sum_{i=1}^{m} P_{i}^{2}}{1-\left(\frac{1}{m}\right)}, \text { where } 0 \leq \mathrm{SIEI} \leq 1
$$

Fragmentation and Scattering in Urban Spatial Structure

We employ perimeter-area fractal dimension (PAFRAC; Krummel et al. 1981) as a metric of space-filling between one- (unfilled) and two- (the fully-compact city) dimensions. Growth in fractal dimension over time is illustrative of compaction; decline suggests fragmentation. Fractal dimension measures have the added benefit of being scale-independent. We calculate fractal dimension as follows.

$$
\text { PAFRAC }=\frac{2}{\left(N \sum_{i=1}^{m} \sum_{j=1}^{n} \ln p_{i j} \ln a_{i j}\right)-\left[\left(\sum_{i=1}^{m} \sum_{j=1}^{n} \ln p_{i j}\right)\left(\sum_{i=1}^{m} \sum_{j=1}^{n} \ln \mathrm{a}_{\mathrm{ij}}\right)\right]}
$$

Where, $N$ is the total number of patches in the landscape. $m$ is the number of landuses $i$ in the study area; $n$ is the number of patches $j . P_{i j}$ is the perimeter of patch $j$ of land-use $i$ and $a_{i j}$ is its area. The denominator in Eq. 5 is the elasticity between patch (local-scale geography) and area (regional-scale geography) obtained by regression.

We also employ metrics to calculate the spatial configuration and structure of urbanization and activities. Contagion (Riitters et al. 1996) is used to measure relative spatial scattering based on per-pixel land-use configuration and an interspersion and juxtaposition index (IJI; Krummel et al. 1981) is used on a per- 
patch basis. Contagion $(C)$ values reach $0 \%$ when distribution of raster adjacencies among unique land-uses becomes uneven and it reaches $100 \%$ when there is maximum fragmentation. Interspersion and juxtaposition (IJI) values may be similarly interpreted, but for patches instead of pixels. Contagion is calculated as follows.

$$
C=1+\frac{\sum_{i=1}^{m} \sum_{j=1}^{n}\left[P_{i}\left(\frac{g_{i k}}{\sum_{k=1}^{m} g_{i k}}\right)\left[\ln P_{i}\left(\frac{g_{i k}}{\sum_{k=1}^{m} g_{i k}}\right)\right]\right]}{2 \ln m} \cdot 100
$$

Where, $m$ denotes the number of land-use types. $n$ is the number of pixels. $g_{i k}$ is the number of adjacencies between pixels of land-use $i$ and $k . P_{i}$ is the proportion of the study area occupied by $i$. Interspersion and juxtaposition is calculated as follows.

$$
\mathrm{IJI}=\frac{-\sum_{i=1}^{m^{\prime}} \sum_{k=i+1}^{m^{\prime}}\left[\left(\frac{e_{i k}}{E}\right) \ln \left(\frac{\mathrm{e}_{\mathrm{ik}}}{\mathrm{E}}\right)\right]}{\ln \left[\frac{1}{2} \mathrm{~m}^{\prime}\left(\mathrm{m}^{\prime}-1\right)\right]} \cdot 100
$$

Where, $m^{\prime}$ is the number of land-use types, including a landscape border. $e_{i k}$ is the length of edge between $i$ and $k$; $E$ is the total edge length in the study area.

\section{Decentralization Characteristics}

We also use spatial autocorrelation metrics to measure decentralization. This is done globally using Moran's $I$ index and is calculated as follows (Fotheringham et al. 2000; Moran 1950).

$$
I=\left(\frac{n}{\sum_{i=1}^{n} \sum_{j=1}^{n} w_{i j}}\right)\left(\frac{\sum_{i=1}^{n} \sum_{j=1}^{n} w_{i j}\left(x_{i}-\bar{x}\right)\left(x_{j}-\bar{x}\right)}{\sum_{i=1}^{n}\left(x_{i}-\bar{x}\right)^{2}}\right), \text { where }-1 \leq I \leq 1
$$

Where $n$ is the number of land parcels considered in analysis. $w_{i j}$ registers adjacency between spatial units $i$ and $j\left(w_{i i}=0 ; w_{i j}=0\right) . x_{i}$ is the value of a variable (sprawl characteristic) analyzed for $i ; x_{j}$ is its value at $j . x$ is the mean value of the same characteristic, considered across all parcels $n$. Positive values of $I$ indicate land parcels that are more similar in value $x$ than the average $y$; negative values indicate dissimilarity. A condition of $I=0$ indicates an absence of statistically-relevant patterning of value $x$ over $i$ and $j$. We would expect a city with global low-density decentralization or high-density compaction to have a value of $I \approx 1$. Expected values 
$E(I)$ and variance $V(I)$ are calculated as follows (Fotheringham et al. 2000; Moran 1950).

$$
\begin{aligned}
E[I]=\frac{-1}{n-1} & \frac{n S_{4}-S_{3} S_{5}}{(n-1)(n-2)(n-3)\left(\sum_{i-1}^{n} \sum_{j=1}^{n} w_{i j}\right)^{2}} \\
V[I]=\frac{\sum_{i-1}^{n} \sum_{j=1}^{n}\left(w_{i j}+w_{j i}\right)^{2}}{2} S_{1} & \frac{\sum_{i=1}^{n}\left(\sum_{j=1}^{n} w_{i j}+\sum_{j=1}^{n} w_{i j}\right)^{2}}{S_{2} \sum_{i=1}^{n}\left(x_{i}-\bar{x}\right)^{4}} \\
S_{3}= & \frac{\left.n^{-1} \sum_{i=1}^{n}\left(x_{1}-\bar{x}\right)^{2}\right)^{2}}{S_{5}=} S_{1}-2 n S_{1}+6\left(\sum_{i=1}^{n} \sum_{j=1}^{n} w_{i j}\right)^{2} \\
S_{4}= & \left(n^{2}-3 n+3\right) S_{1}-n S_{2}+3\left(\sum_{i=1}^{n} \sum_{j=1}^{n} w_{i j}\right)^{2}
\end{aligned}
$$

We also examine decentralization on a per-parcel level using local values of Moran's $I\left(I_{i}\right)$ and a localized Getis-Ord $G$ statistic (Anselin 1995; Getis and Ord 1992) $\left(G_{i}\right) . I_{i}$ is calculated as follows (Anselin 1995).

$$
\left.\begin{array}{l}
I_{i}=\left(\frac{x_{i}}{m_{2}}\right) \sum_{i=1}^{n} w_{i j} x_{j} \\
m_{2}=\sum_{i=1}^{n} \frac{x_{i}^{2}}{n}
\end{array}\right\}, \text { where } \sum_{i=1}^{n} I_{i}=\mathrm{I} \text { from equation }(\mathrm{i}) \text { and }-1 \leq I \leq 1
$$

Where, $I_{i}$ is the local Moran's $I$ value for parcel $i$ (these local values average to the global $I$ ) and the definitions of the other terms remain as specified before. Expected value and variance $\left(E\left[I_{i}\right]\right.$ and $\left.V\left[I_{i}\right]\right)$ are calculated as follows (Anselin 1995).

$$
E\left[I_{i}\right]=\frac{-w_{i}}{(n-1)}
$$




$$
\left.\begin{array}{rl}
V\left[I_{i}\right] & =\frac{w_{i(2)}\left(n-b_{2}\right)}{(n-1)}+\frac{2 w_{i(k h)} 2\left(b_{2}-n\right)}{\frac{(n-1)(n-2)-w_{i}^{2}}{(n-1)^{2}}} \\
w_{i(2)} & =\sum_{j \neq i}^{n} w_{i j}^{2} \\
b_{2} & =\frac{m_{4}}{m_{2}^{2}} \\
2 w_{i(k h)} & =\sum_{k \neq i}^{n} \sum_{h \neq i}^{n} w_{i k} w_{i h} \\
m_{4} & =\sum_{i=1}^{n} \frac{x_{i}^{4}}{n}
\end{array}\right\}
$$

$w_{i}$ in Eq. 12 is the sum of row elements in an adjacency matrix $w_{i j}, \sum_{j=1}^{n} w_{i j} \cdot k$ and
$h$ are point locations. $m_{2}$ is as defined in Eq. 11 .

The local test of Getis-Ord spatial autocorrelation is formulated as follows (Wong and Lee 2005).

$$
G_{i}(d)=\frac{\sum_{j} w_{i j}(d) x_{j}}{\sum_{j} x_{j}}, j \neq i \text { and } W_{i}=\sum_{j} w_{i j}(d)
$$

Where, $G_{i}(d)$ measures local spatial autocorrelation within a distance threshold $d$. Highly positive values of $G_{i}(d)$ point to spatial clustering of high values of $x$ (hotspots), while highly negative values suggest spatial clustering of low values (coolspots; Wong and Lee 2005). $i$ and $j$ are considered neighbors if they are $<d$ apart. $w_{i j}(d)=1$ if $j$ is within distance $d$ of $i$, otherwise $w_{i j}(d)=0$.

The expected value and variance of $G_{i}$ are calculated as follows (Wong and Lee 2005).

$$
\begin{gathered}
E\left[G_{i}\right]=\frac{W_{i}}{(n-1)}, \text { where } W_{i}=\sum_{j=1}^{n} w_{i j}(d) \\
V\left[G_{i}\right]=E\left(G_{i}^{2}\right)-\left[E\left(G_{i}\right)\right]^{2} \\
\left.E\left(G_{i}^{2}\right)=\frac{1}{\left(\sum_{j=1}^{n} x_{j}\right)^{2}}\left[\frac{W_{i}\left(n-1-W_{i}\right) \sum_{j=1}^{n} x_{j}^{2}}{(n-1)(n-2)}\right]+\frac{W_{i}\left(W_{i}-1\right)}{(n-1)(n-2)}\right\}, \text { where }, j \neq i
\end{gathered}
$$

Accessibility Characteristics

Accessibility is calculated as straight-line and road network distance to a range of urban opportunities: the CBD, schools, other education opportunities (colleges, 
libraries, museums), and locally-unwanted land-uses (LULUs; airports, water treatment plants, electrical plants, wastewater facilities, correctional facilities). The CBD is defined as the point in downtown Austin that minimizes straight-line distance to all hotels that are mentioned as being situated downtown in promotional material.

\section{Results and Findings}

Our methodology is capable of capturing each of the characteristics of sprawl that are popularly-debated in the literature (Tables 1 and 2). Each characteristic yields a unique view of the city's evolution: pointing to sprawl in some places but not others and in some characteristics but not others. Collective examination of the characteristics allows us to assess the relative role played by various forces in shaping sprawl (or not), with the potential added benefit of empirically evaluating the efficacy of growth management strategies.

\section{Sprawl Indicators in Urban Growth Characteristics}

Austin exhibits classic signatures of suburban sprawl in its growth characteristics. The volume of land occupied by urban growth grew markedly between 1990 and 2000. This is illustrated in Fig. 1, which shows urbanization from 1990 to 2000 in 5year increments. Note that the graphics in Fig. 1 illustrate the addition of new urbanization, not the existing footprint of the city. The implications of rapid growth are clearly evident in the extension of developable land between 1990 and 2000 (Fig. 1d,e). The city grew to almost twice its developable area in just 10 years. A marked extension of the effective range of the city for development is clearly evident in Fig. 1d and e.

The pace of urbanization was dramatic. The population of Austin-Round Rock MSA grew by $47.7 \%$ between 1990 and 2000, and 16.2\% between 2000 and 2005, which ranks among the highest growth rates for all US MSAs. Our findings show that the population growth was diffused through the Texan landscape, spatially, at a rapid pace. The spatial expansion of the city is shown in snapshot in Fig. 1. Note again that Fig. 1a-c show the spatial positioning of new urbanization, rather than the preexisting urban footprint. Urbanization diffused voraciously through the city over an omnidirectional range of 35 miles from the CBD from 1990 to 1995, and the diffusion of urbanization extended a further 20 miles from 1995 to 2000 . Addition of developable land doubled from 1995 to 2000, as shown in Fig. 1d and e.

The tell-tale signs of suburban sprawl are also evident in the position of urbanization and urban growth. The periphery stands out as the area where new urbanization takes place with the greatest spatial range and the fastest rate of expansion. This is clear in Fig. 1a-c, which charts the accretion of an orbiting volume of newly-urbanized land on the fringes of the preexisting urban mass.

Vestiges of leapfrogging are also evident in urban growth. Large swaths of land are bypassed by the urbanization machine, as shown in Fig. 1a-c.

The signs of sprawl in the city's growth are also clear when examining the uses to which the newly-urbanized land is put. Figure 2 shows the spatial footprint of low- 
density residential settlement in and around Austin from 1990 to 2000. When we consider Figs. 1 and 2 in tandem, it is clear that the urbanization on the periphery in Fig. 1 is dominated by residential uses at low densities, a classic indicator of suburban sprawl.

Very little new urbanization occurred in the central city between 1990 and 2000, likely because it had already urbanized in a compact fashion. A relatively small area of residential land was added to the central city (Fig. 2). The central city did,
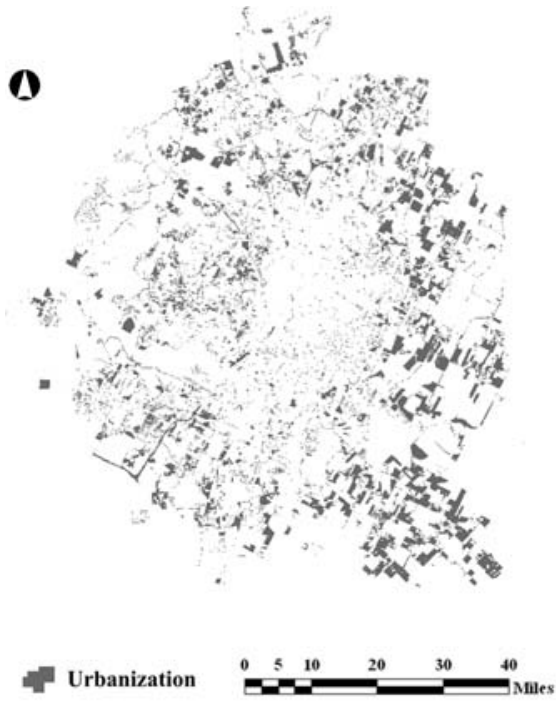

a
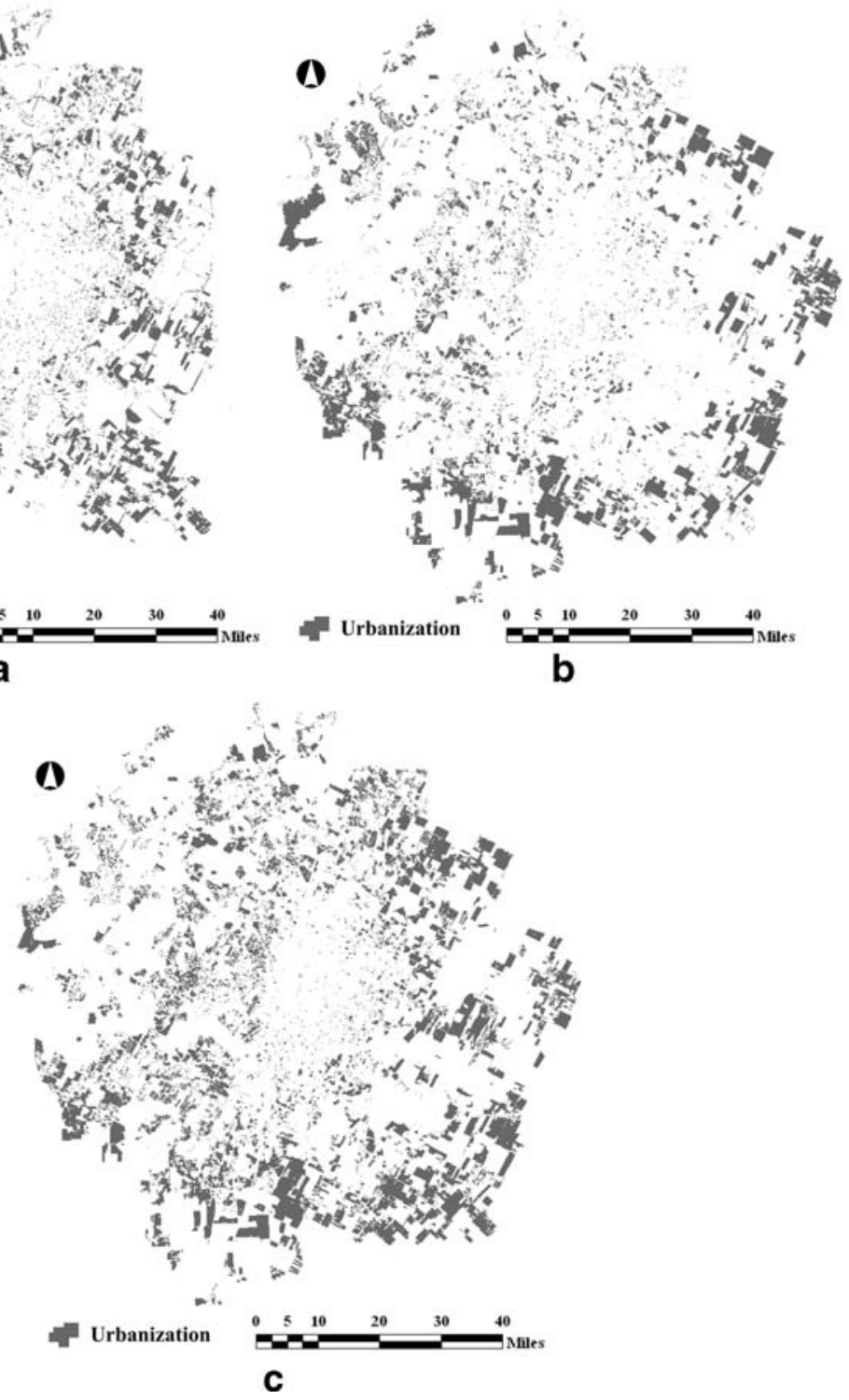

Fig. 1 Urbanization, a 1990 to 1995, b 1995 to 2000, c 1990 to 2000; developable land, d 1995, e 2000 

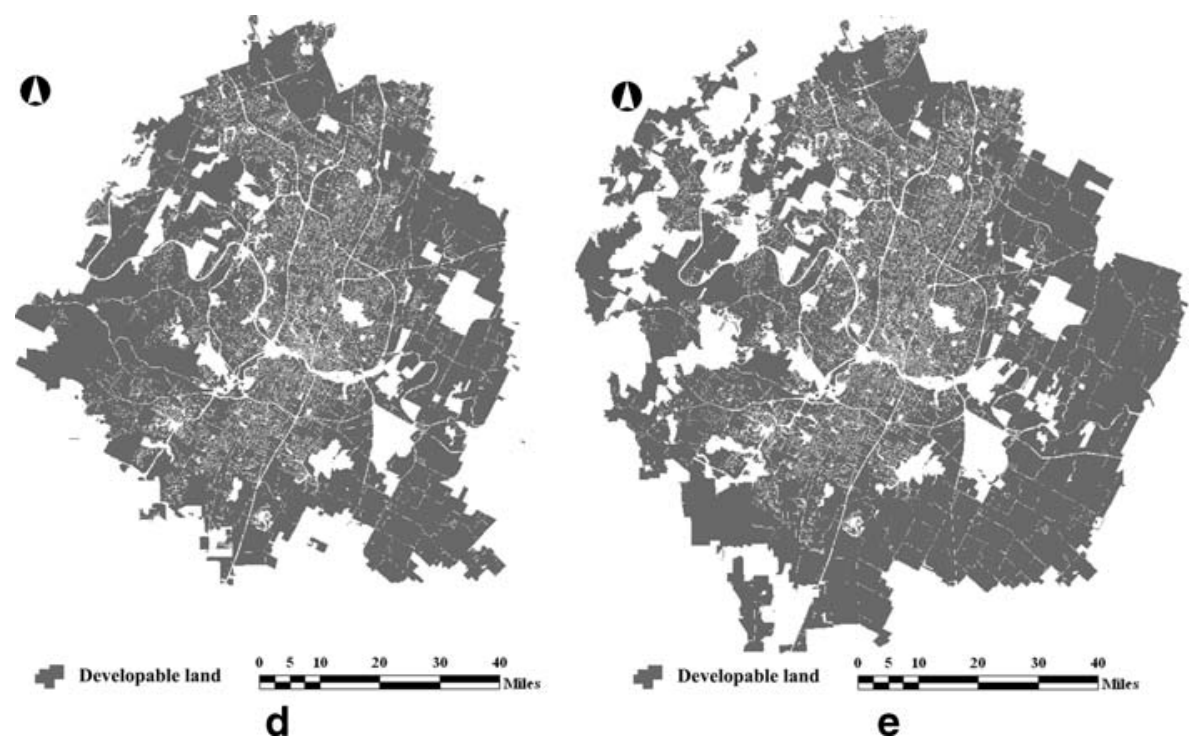

Fig. 1 (Continued)

however, become more densely settled from 1990 to 2000; while the suburbs expanded outward, the central city expanded upward.

Signs of Sprawl in Social Characteristics

To the extent that residential tenure serves as a proxy for social characteristics (renter-occupation, particularly outside the $\mathrm{CBD}$, perhaps indicating less affluent households than owner-occupation), our findings show dramatic socio-spatial separation in Austin. The newly-urbanizing suburban belt is socially distinct from the central interior. Renter-occupation dominates in the dense central city, but yields to owner-occupation in the suburbs. The contrast is distinct, owner-occupation drops abruptly 15 (road network) miles from the CBD, with a dramatic shift toward renteroccupation within a central 10-mile ring (Fig. 3).

Vestiges of Sprawl in the City's Centralization and Decentralization Characteristics

The tests for centralization and decentralization in Austin yield mixed results synoptically: the city has succumbed to both forces of centralization and decentralization at regional scale. This finding is supported by the results of global spatial autocorrelation analysis. The city exhibited weakly positive global spatial autocorrelation with respect to population density over the study period, indicating independent collocation of low-density areas and collocation of high-density areas. The Moran's $I$ values for global spatial autocorrelation are shown in Table 4. Across all land, $I$ values were 0.1893 and 0.246 ( $I$ can take on values between +1 and -1 ) in 1990 and 2000 respectively, a change of +0.0567 . The change in $I$ for developable land was +0.0677 . The amount of change in $I$ is negligible on both counts. 
The picture is quite different when considered at a finer-scale resolution, however. Locally, Austin is shown to host a central interior core that is centralizing further through centripetal action. This stands in stark contrast to local centrifugal decentralization in the ambient suburbs. The urban interior lacks the characteristic doughnut effect (in infrastructure density and population density) of other sprawling cities. Austin's downtown core has apparently remained viably compact over time, growing increasingly so in the face of sprawl. These observations are supported by our local analysis of spatial autocorrelation, again across net and gross land. The downtown core exhibited high-high local spatial autocorrelation (areas of high density tend to collocate with other areas of high density). The peripheral areas show

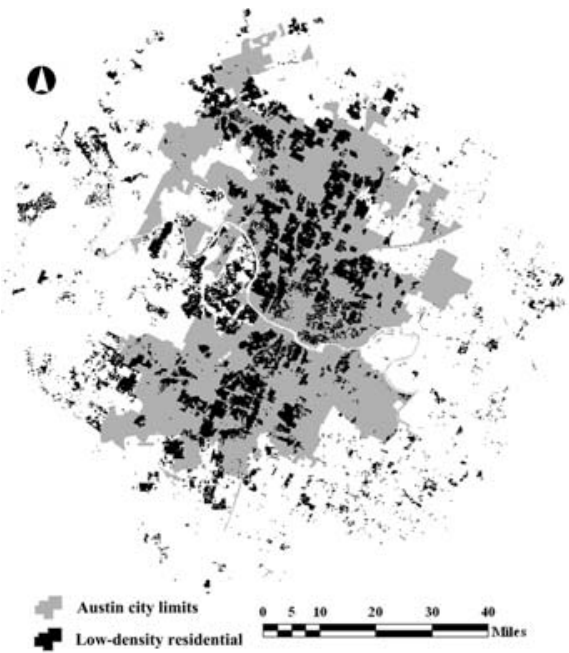

a

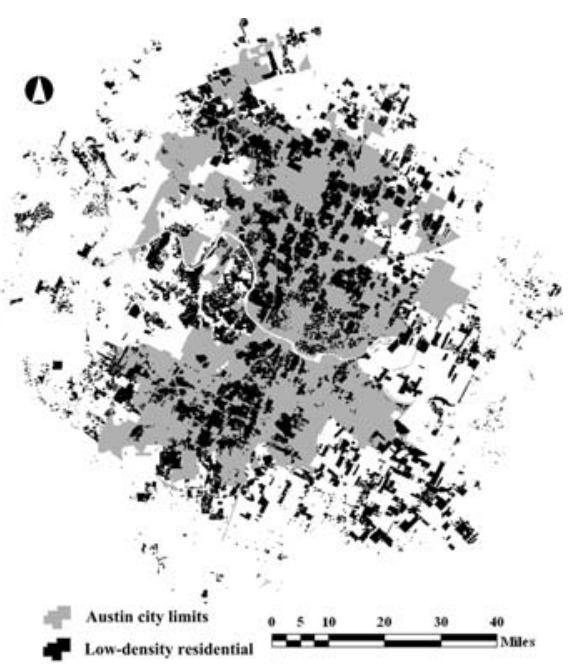

b

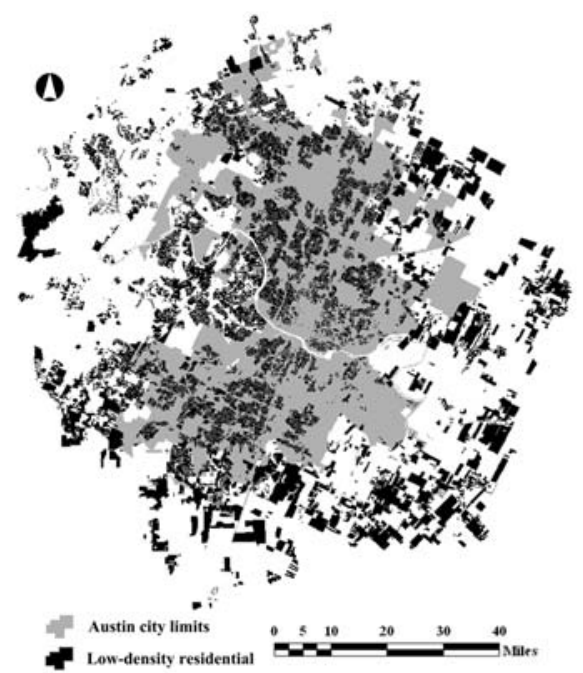

C

Fig. 2 Low-density residential land-use, a 1990; b 1995; c 2000 

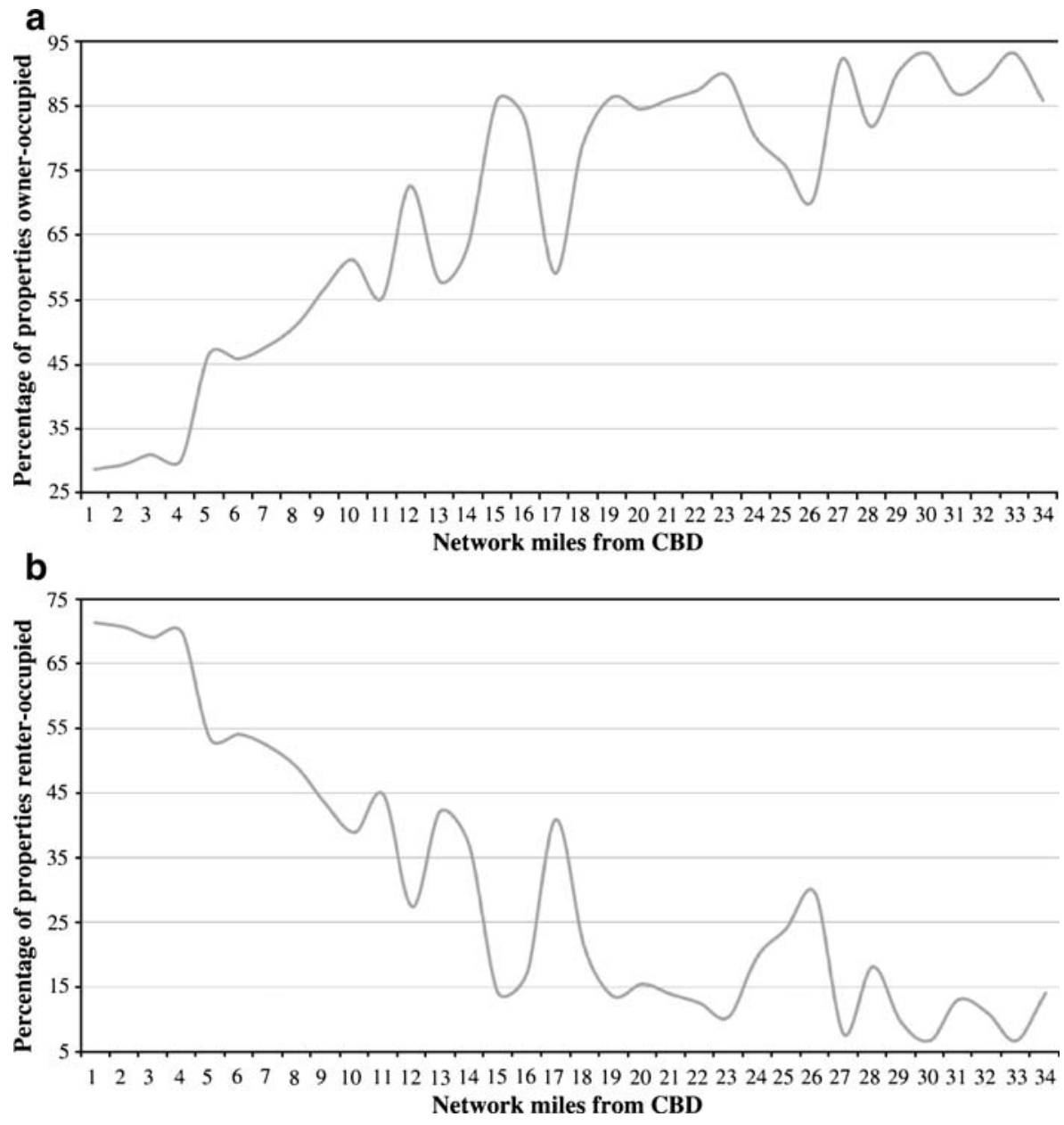

Fig. 3 Tenure profiles. a Owner-occupation; b renter-occupation

low-low local spatial autocorrelation; areas of low density tend to be found adjacent to other areas of low density. This implies that density is systematically spatially concentrated in distinct clusters. The central city plays host to high density clusters, while the ambient suburbs host the low density clusters. A mixed-density buffer separates them. This is evident in Fig. 4, which shows the areas of local spatial association by two metrics (the local Moran's I, $I_{i}$, and a local Getis-Ord measure of spatial association, $G_{i}$ ). The graphic in Fig. 4 shows a clear concentration of high density (as measured for both local statistics) in the downtown area, clustering of low density in the suburbs, and a swath of mixed activity in the interstitial area between central city and suburbs (this explains why the global value of spatial autocorrelation was not more strongly positive - areas buffering the CBD yielded mixed results, or were found to be statistically non-significant). The global measures of spatial autocorrelation show that the tendency for positive spatial autocorrelation 를 Springer 
Table 4 Moran's $I$ values

\begin{tabular}{llll}
\hline & $\mathbf{1 9 9 0}$ & $\mathbf{2 0 0 0}$ & Change \\
\hline All land & & & 0.0567 \\
Moran's I & 0.1893 & 0.246 & 0.001 \\
Expected Moran's I (999 permutations) & -0.0001 & 0.0059 & 0.001 \\
Standard deviation & 0.0054 & & 0.0677 \\
$p$ value & 0.001 & 0.2242 & -0.0001 \\
Developable land & & 0.1565 & \\
Moran's I & -0.0001 & 0.0069 & \\
Expected Moran's I (999 permutations) & 0.0072 & 0.001 & \\
Standard deviation & & & \\
$p$ value &
\end{tabular}

increased from 1990 to 2000, although only marginally: low- and high-density clustering became more entrenched.

\section{Sprawl Signatures in the Accessibility Profile of the City}

Austin's core has remained accessible in the face of sprawl. Almost ubiquitous general accessibility was found across the city (Figs. 5, 6, 7, 8 and 9), supporting a thesis by Giuliano (1989) that the influence of accessibility (for those who can afford a car) is being diluted in American cities by road provision.

The CBD is relatively accessible by vehicle from most of the city. The outlying areas of the urban transport system provide accessibility to the downtown within six network miles (Fig. 5). Recall from the discussion in "Introduction" that provision of accessibility city-wide in a targeted panacea for sprawl in the city's smart growth policy. Corridors of very high accessibility buffer the city's highway network, although interstitial areas between highway arterials are relatively poorly-served by

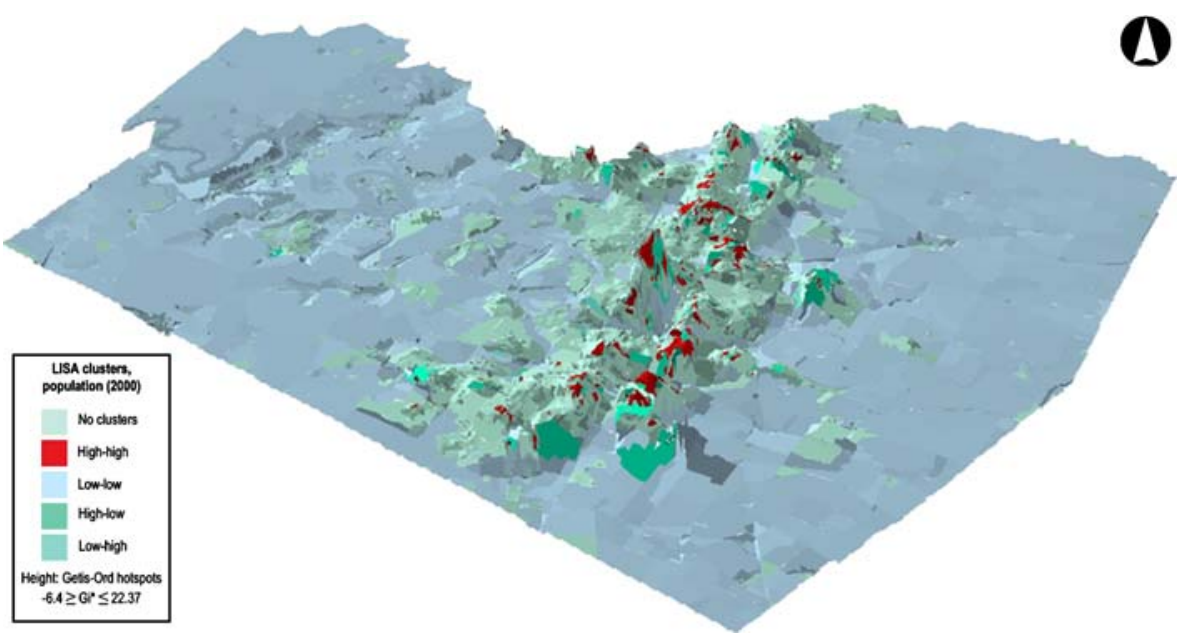

Fig. 4 LISA clusters for population (2000; coloring indicates local Moran's I clusters; height represents local Getis-Ord clusters) 


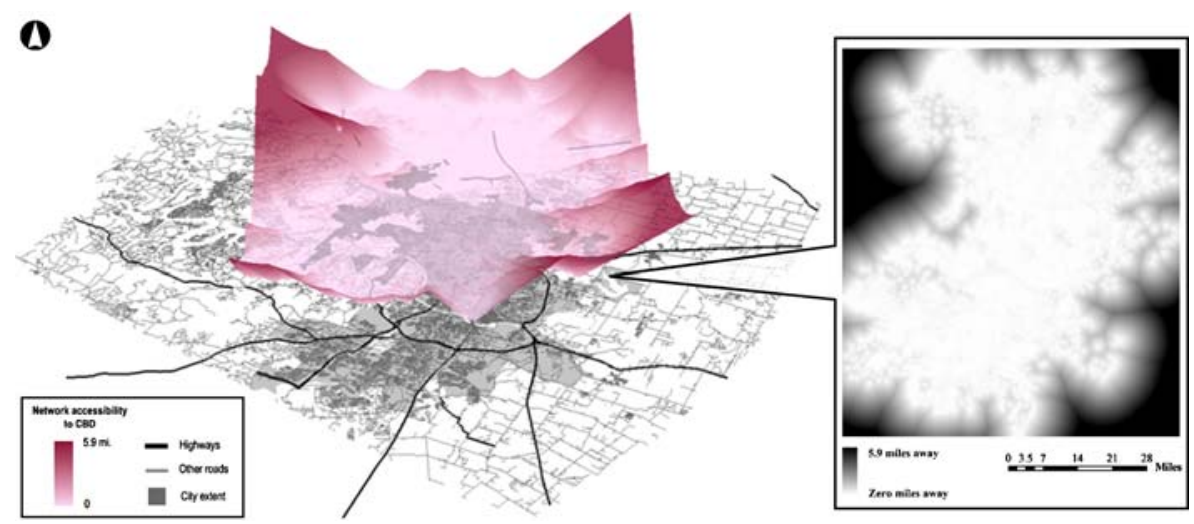

Fig. 5 Network accessibility to the CBD (the callout shows the accessibility surface in 2D)

accessibility to the downtown (the fin-like ridges in the accessibility surface shown in Fig. 5).

Employment is geographically diffuse across the city. The accessibility surface for employment is flat throughout most of the urban area, and only becomes steep on the outskirts of the metropolitan area. The flat profile on Fig. 6 indicates areas of high accessibility. There were 132 employers with 500 employees or more per business in the metropolitan area in 2000. For the most part, employers are concentrated in the city of Austin, with a handful of employers in the exurban area on the edge of the city (Fig. 6). Sprawl has been associated with job flight toward suburban locations (Ewing 1994, 1997) and we would expect, on this basis, to find a pattern of job decentralization. A plethora of jobs are to be found in the central city, however (Fig. 6). Moreover, jobs are reasonably accessible city-wide.

The same pattern is evident in our findings for accessibility to education opportunities. Schools are almost universally accessible throughout the metropolitan area. The accessibility surface climbs on the outskirts of the city, in mostly rural

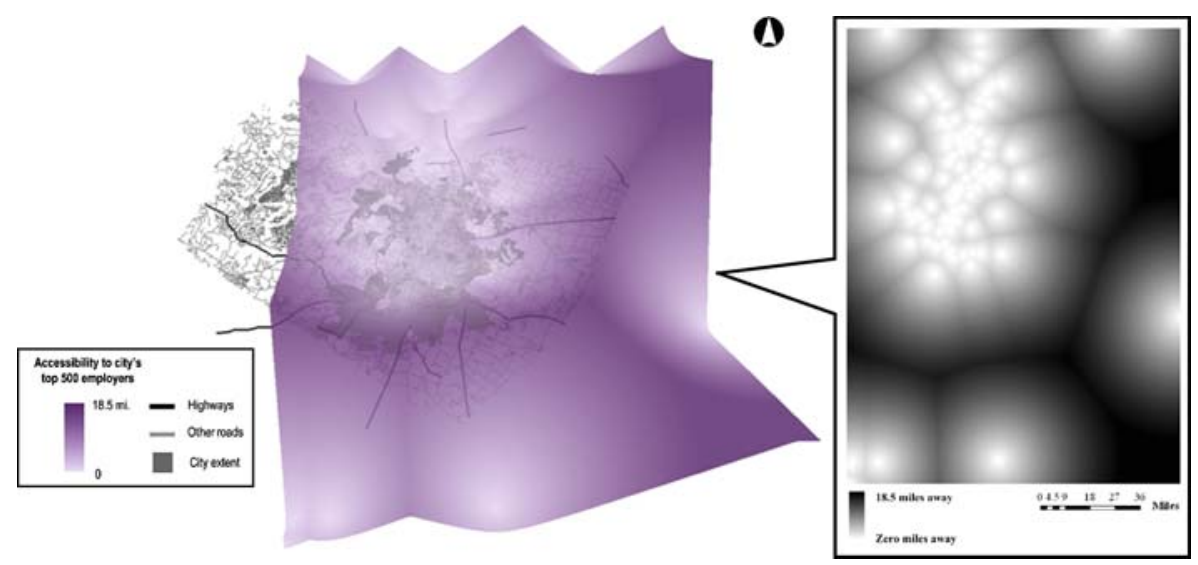

Fig. 6 Straight-line accessibility to employers with over 500 employees (132; the callout shows the accessibility surface in 2D) 


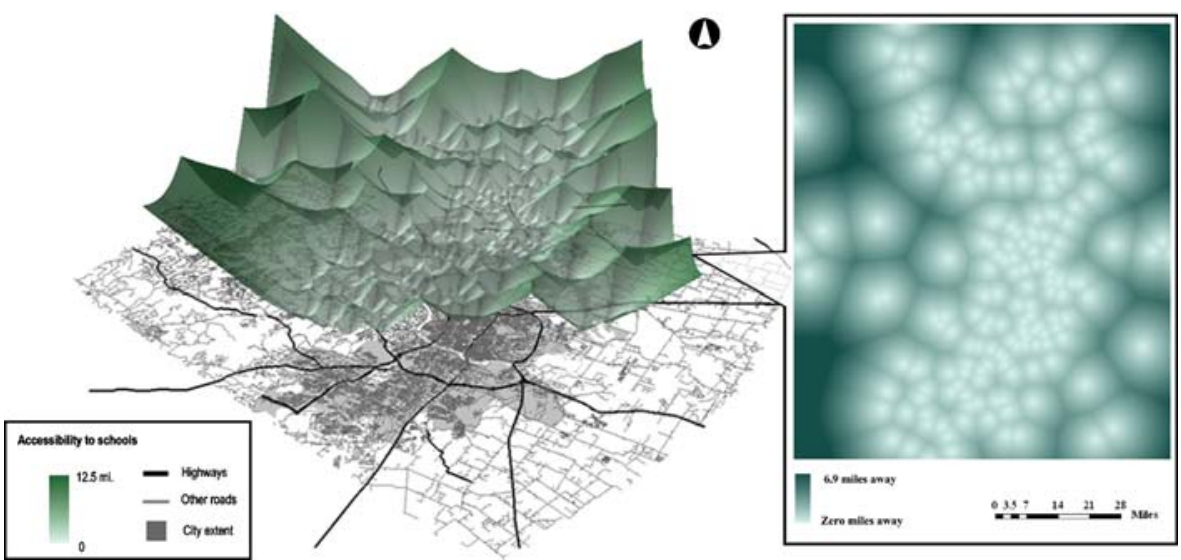

Fig. 7 Straight-line accessibility to schools (the callout shows the accessibility surface in 2D)

areas. The central city in particular is well-endowed with ease of access to schools (Fig. 7).

There is some variation in this pattern with respect to accessibility to other educational opportunities (universities, colleges, libraries, museums), which are very accessible in the central city. The western side of the city has reduced accessibility, although this is likely because two sites are to be found at some distance from the main cluster of opportunities in the downtown core (Fig. 8).

It is only when locally-unwanted land-uses (LULUs; airports, water treatment plants, electrical plants, wastewater facilities, correctional facilities) are examined that we begin to see classic sprawl signatures in the city's accessibility surface. Ease of accessibility to LULUs is concentrated in the downtown core of the city and on the western side of the city. Residents in these areas are, theoretically, susceptible to the influence of unwanted land-uses with a greater likelihood than residents living

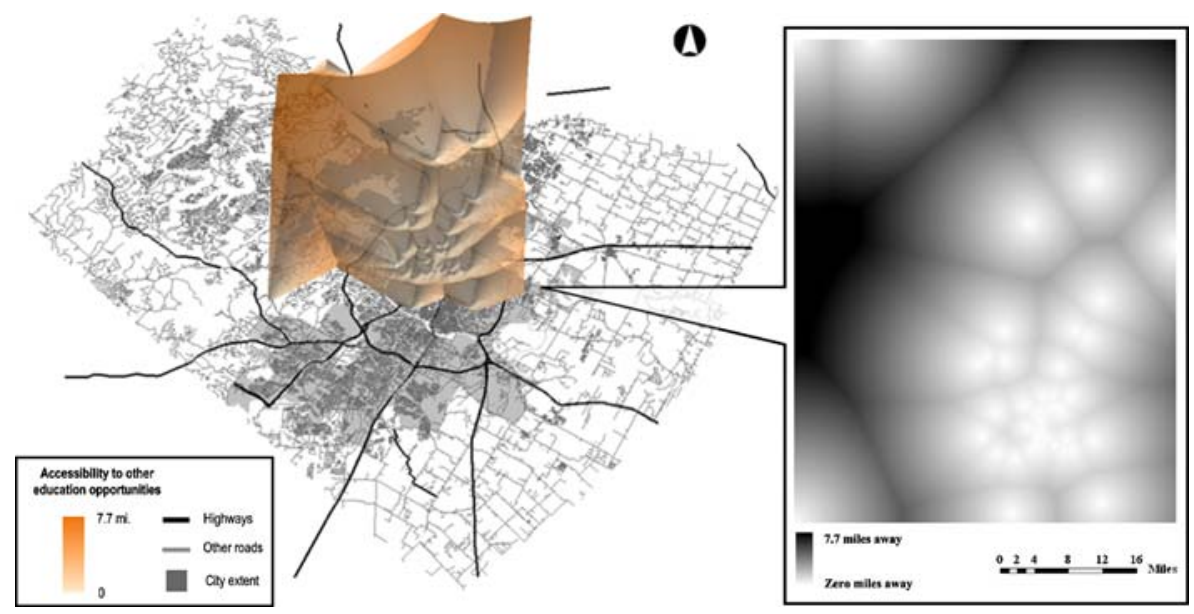

Fig. 8 Straight-line accessibility to other educational opportunities (the callout shows the accessibility surface in 2D) 


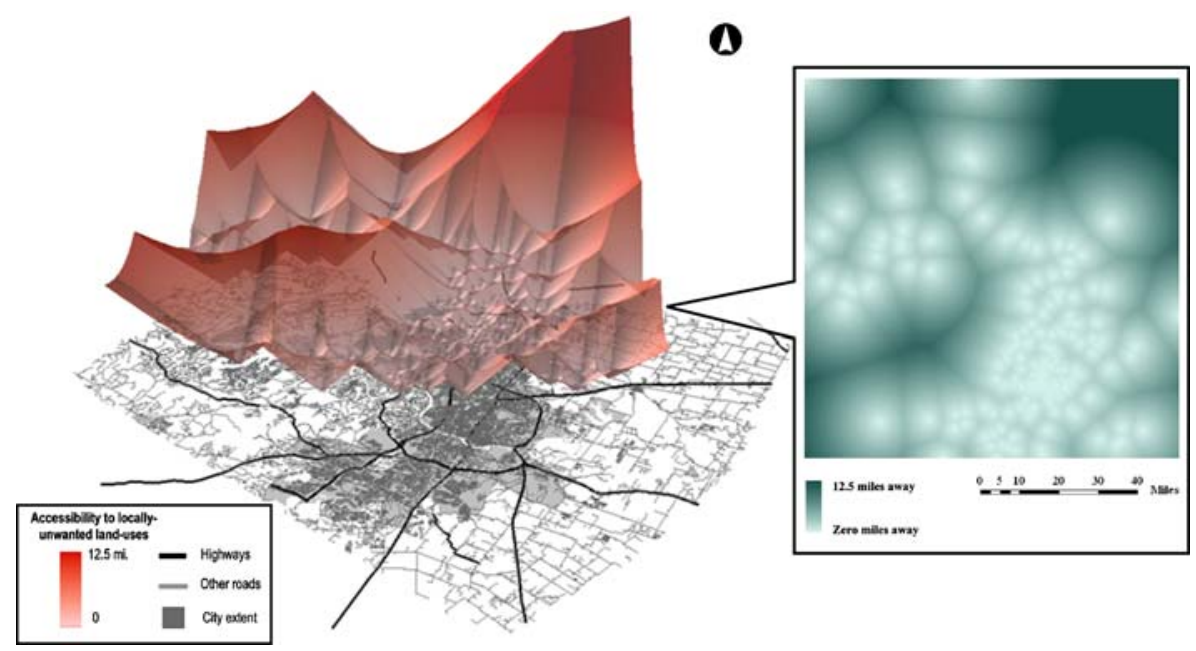

Fig. 9 Straight-line accessibility to locally-unwanted land-uses (the callout shows the accessibility surface in 2D)

elsewhere in the city. In particular, the northern and western suburbs are relatively free from accessible LULUs (Fig. 9).

\section{Sprawl Indices in Urban Density}

Density characteristics were examined (visually and statistically) using density profiles as well as density surfaces. The density profile compresses information from two dimensions of the city's geography to one dimension (recall from the methodology section that data for the profile are polled from concentric bands around the city's CBD). It shows us where a phase-shift in the city's population, housing, and family density occurs. The density profiles for the city are illustrated visually in Fig. 10 and empirically in Tables 5 and 6. There is a clear distinction in Fig. 10 between the density of the central city and that of the ambient suburbs. The central city is characterized by relatively high density and the profile tapers dramatically outside of the core, adopting a flat profile in the suburbs and out to the exurban fringe. There are some minor "bumps" in the profile on the edge of the downtown. Bumps in the exurban part of the profile $(>$ mile 30) are present where isolated dense settlements raise the profile for that band of distance from the CBD. These are likely edge city phenomena, at least in prototypical form (Garreau 1992). These profiles illustrate a monocentric structure to the city, considered metropolitanwide. The transition from high- to low-density is sharp at a 10-mile radius from the central interior, dropping dramatically thereafter to a plateau that extends toward the urban periphery. The same pattern is evident regardless of whether we measure net or gross density (Fig. 10a and c respectively) and holds relatively stable for population, housing, or family density. The 10-mile mark is where a phase shift of sorts takes hold: we believe this to be where sprawl begins in the city.

Analysis by OLS and spatial regression shows a gently- and negatively-sloping density gradient for the city, considered across net and gross land. Elasticity in the 


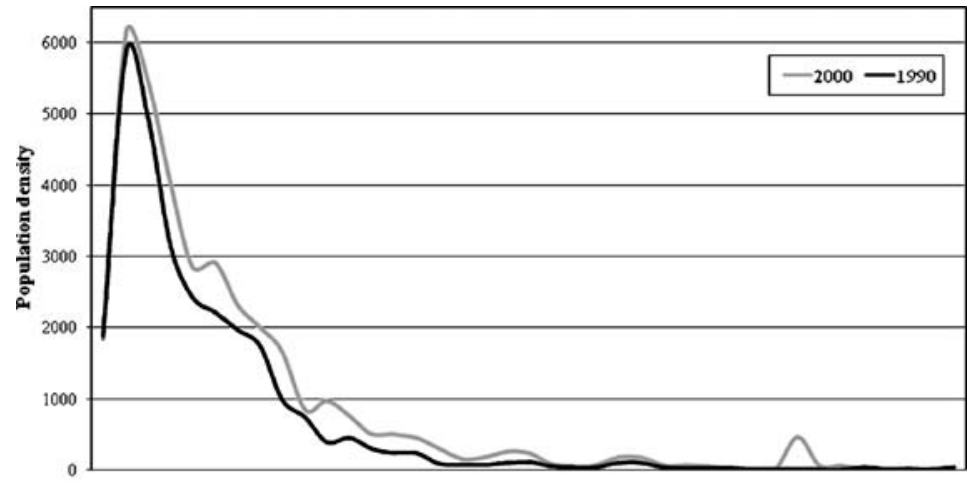

$123445678 \quad 9101112131415161718192021222324252627282930313233343536373839$ Network miles from CBD

a

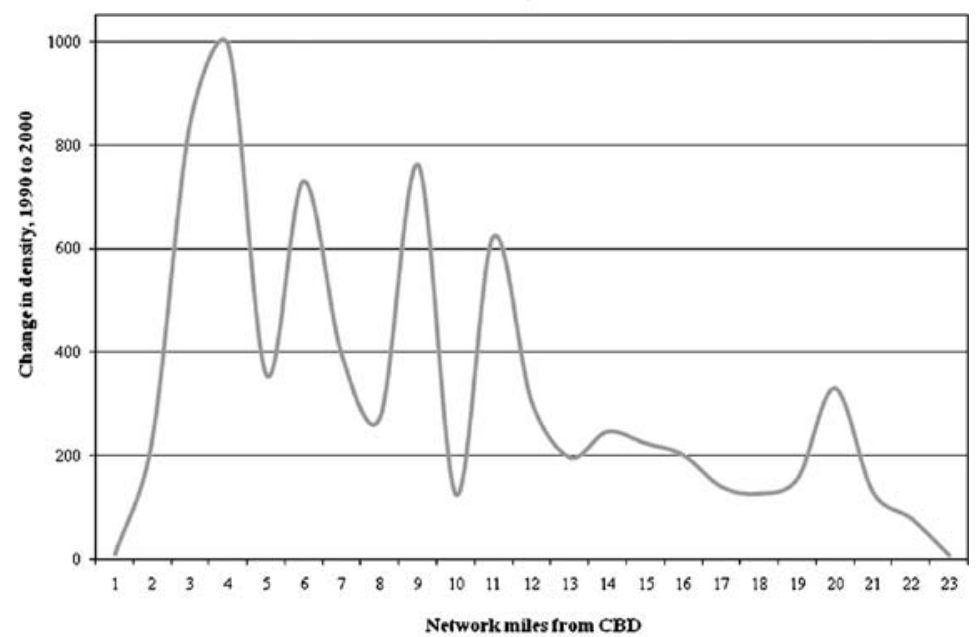

b

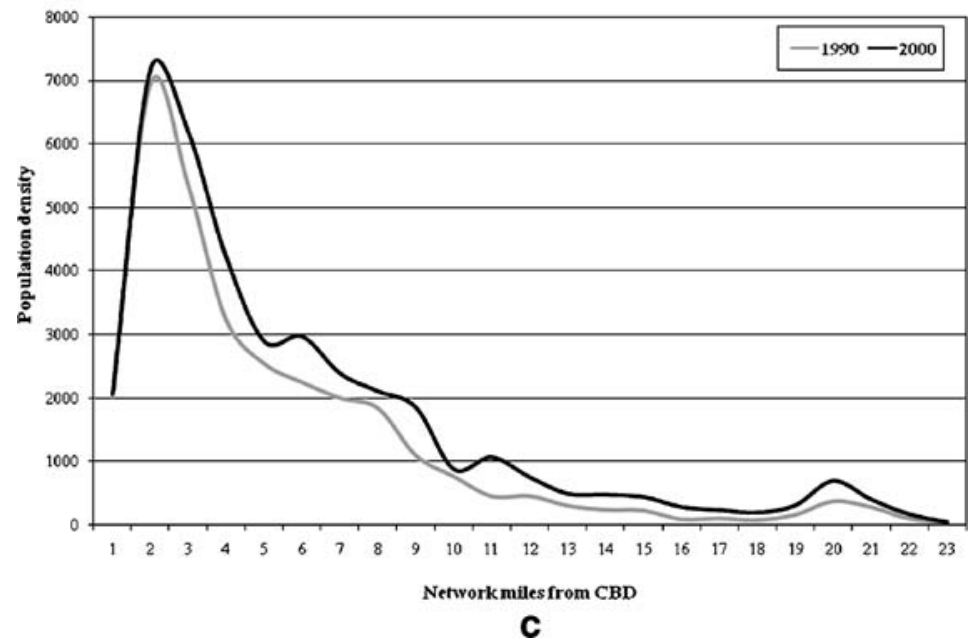

Fig. 10 Density profiles. a All land; b change, all land; c developable land; d housing unit; e family 

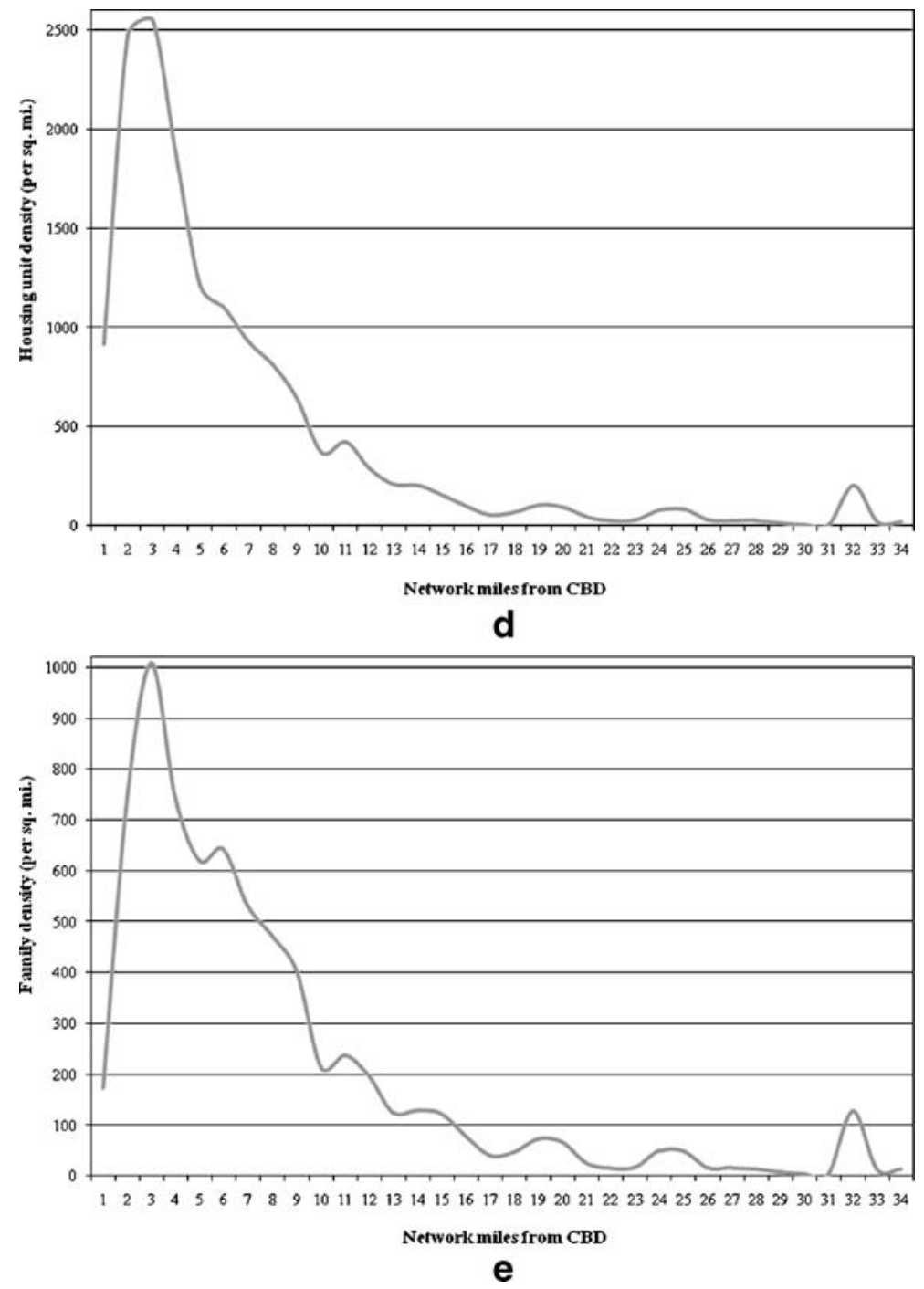

Fig. 10 (Continued)

relationship between unit density (number of people) and distance (miles) was estimated as -0.024 for the year 2000 by OLS and -0.011 by spatial regression. Spatial regression yields a gradient that is larger than that estimated by OLS regression by a factor of 1.75 over all land (Tables 5 and 6). OLS regression underestimates central density (the value of the constant in Tables 5 and 6 , or where $d=0$ in the model represented by Eq. 1. Constant values are quite high because data were derived from parcel records, i.e., at small scales, but reported per square mile.), spatial regression over-estimates it.

The results of density surface analysis cast additional light on the geography of density in Austin. The surface analysis shows that Austin has a degree of 黑 Springer 
Table 5 Density gradients by OLS regression

\begin{tabular}{llll}
\hline & $\mathbf{1 9 9 0}$ & $\mathbf{2 0 0 0}$ & Change \\
\hline All land & & \\
Number of observations & 9,396 & 11,292 \\
Constant & $6,075.071$ & $6,436.681$ & $5,492.000$ \\
Known CBD density & $5,864.750$ & -0.046 \\
Distance & -0.054 & $7,698.420$ & 0.008 \\
Std. error of the regression & $7,031.640$ & 143.625 \\
$F$-statistic & 500.335 & 0.000 \\
Prob $F$-statistic $)$ & 0.000 & 0.033 \\
$R$-squared & 0.051 & 0.033 \\
Adjusted $R$-squared & 0.050 & \\
Developable land & & 8,975 \\
Number of observations & 7,663 & $6,169.074$ \\
Constant & $6,177.819$ & 5492.000 \\
Known CBD density & $5,864.750$ & -0.029 \\
Distance & -0.051 & $8,156.560$ \\
Std. error of the regression & $7,698.420$ & 53.374 \\
$F$-statistic & 143.625 & 0.000 \\
Prob $(F$-statistic) & 0.000 & 0.006 \\
$R$-squared & 0.018 & 0.006 \\
Adjusted $R$-squared & 0.018 & \\
\hline
\end{tabular}

polycentricity that that does not present itself in the profile analyses. In particular, the city is shown to be polycentric within its center on an intra-urban basis; its monocentric core is quite polycentric within. This is shown in Figs. 11 and 12. The surface density for the central city is relatively lumpy and the inner suburbs show several smaller sub-cores of density.

Analysis of changes to that surface demonstrated a long-term reinforcement of the overall pattern just described. For the most part, these changes took on the form of density growth and further compaction in the central city, with a sprinkling of

Table 6 Density gradients by spatial regression

\begin{tabular}{llll}
\hline & $\mathbf{1 9 9 0}$ & $\mathbf{2 0 0 0}$ & Change \\
\hline All land & & & \\
Number of observations & 9,396 & 11,292 \\
Constant & $4,353.177$ & $3,654.354$ & 0.014 \\
Known CBD density & $5,864.750$ & 5,492 & \\
Distance & -0.038 & -0.024 & 0.461 \\
$W$ (density) & 0.3 & $7,085.41$ & \\
Std. error of the regression & $6,810.01$ & 0.172 \\
$R$-squared & 0.109 & & \\
Developable land & & 8,975 \\
Number of observations & 7,663 & $3,525.872$ \\
Constant & $4,552.949$ & 5,492 \\
Known CBD density & $5,864.750$ & -0.011 \\
Distance & -0.035 & 0.436 \\
$W$ (density) & 0.269 & $7,580.89$ \\
Std. error of the regression & $7,491.75$ & 0.141 \\
$R$-squared & 0.07 & \\
\hline
\end{tabular}



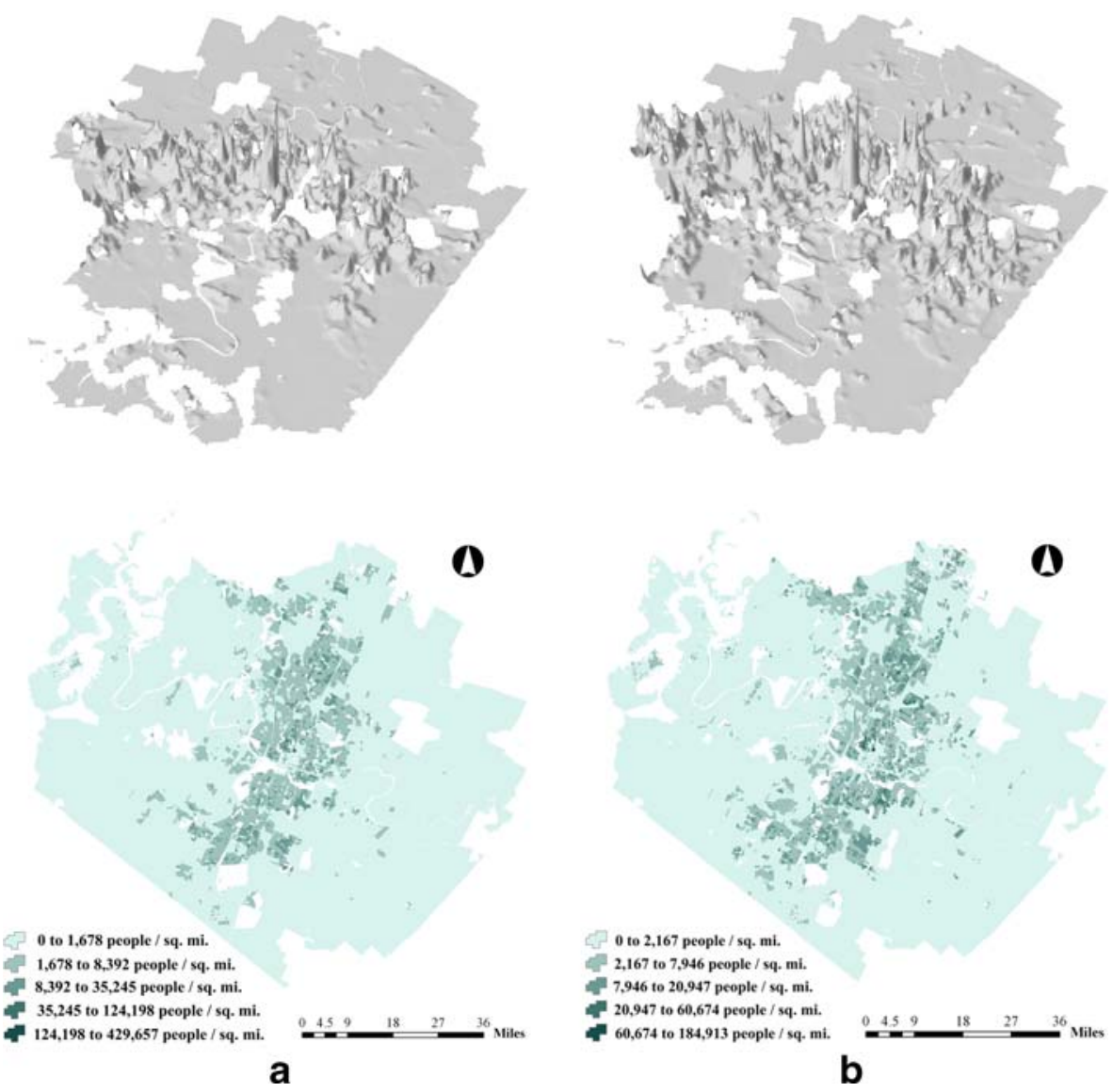

Fig. 11 Population density, developable land, a 1990; b 2000

polynucleated density in the suburbs [likely edge cities or edge towns (Garreau 1992)] (Fig. 12).

Changes in the results of these analyses are crucial to understanding the city's evolution. The city's density profile has clearly flattened over time (Fig. 10). The distance-decay, as reported by regression analysis, flattened from -0.038 to -0.024 (by OLS) and from -0.035 to -0.011 (by spatial regression) from 1990 to 2000 . These changes of +0.014 and +0.024 respectively (Tables 5 and 6) point to a relatively prominent and significant flattening of the city's density profile over a decade. Population numbers in 1990 fell by one person along the profile for every 0.038 to 0.035 miles (200 to $185 \mathrm{ft}$; by OLS and spatial estimation respectively), considered omnidirectionally with increasing distance from the CBD. In 2000 the population dropped by one person for every 0.024 to 0.011 miles (127 to $59 \mathrm{ft}$; by OLS and spatial estimation respectively). This has likely occurred because the reach of the suburbs, settled with low densities, has grown to encompass a greater band of peripheral urbanization around the edge of the city (Figs. 1 and 2). At the same time, the downtown core of the city has added considerable population density in some 


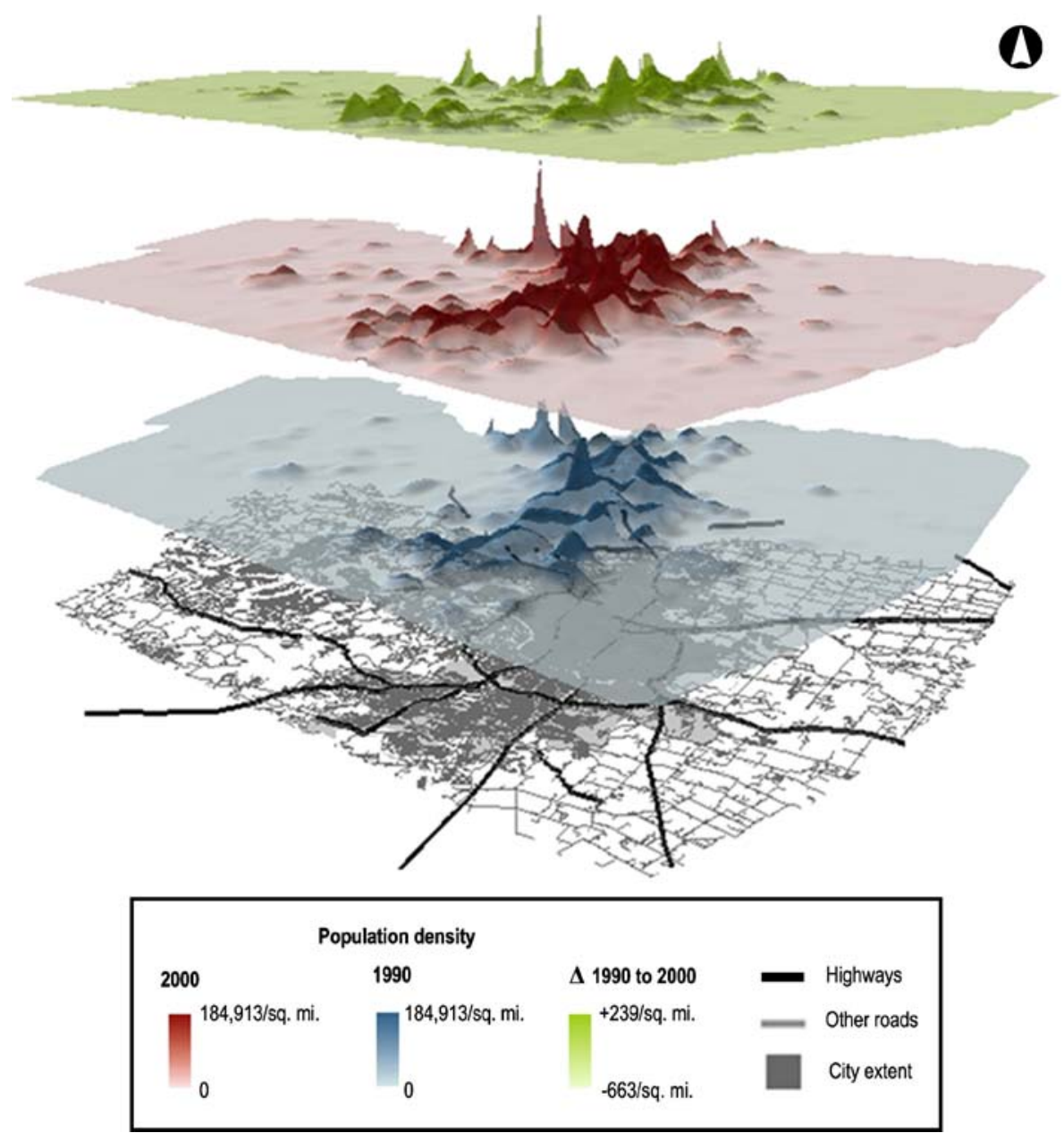

Fig. 12 Population density

places (although not all) and there has been growth in density in a sprinkled fashion among the inner suburbs (as shown in Fig. 12). Only a handful of locations lost density from 1990 to 2000 .

Signs of Sprawl in Urban Fragmentation

Overall, fragmentation is evident in the changing number of urban patches in the city. Patches are spatially-coherent "blobs" of land-use activity. As reported in Table 7, the number of patches decreased across most land-uses over the study period while the total number of patches of urban land grew (Table 8). This is illustrative of increased spatial scattering and growing isolation of urban areas, but with compaction of land-uses within those patches. The total growth in urban patches was 5,703 between 1990 and 2000 and, as shown in Table 8, much of it occurred between 1990 and 1995. This shows that the city became increasingly 
Table 7 Number of land-use patches

\begin{tabular}{|c|c|c|c|c|}
\hline Land-use & 2000 & 1995 & \% change, 1995 to 2000 & Change, 1995 to 2000 \\
\hline Civic & 1457 & 2113 & $-31.05 \%$ & -656 \\
\hline Commercial & 5312 & 6488 & $-18.13 \%$ & -1176 \\
\hline Industrial & 2164 & 2561 & $-15.5 \%$ & -397 \\
\hline Large-lot single-family & 7 & 49 & $-85.7 \%$ & -42 \\
\hline Mining & 100 & 111 & $-9.91 \%$ & -11 \\
\hline Mobile homes & 1242 & 1228 & $+1.14 \%$ & +14 \\
\hline Multi-family & 6053 & 6318 & $-4.19 \%$ & -265 \\
\hline Office & 1809 & 2123 & $-14.8 \%$ & -314 \\
\hline Open space & 1587 & 1990 & $-20.25 \%$ & -403 \\
\hline Single-family & 147961 & 156792 & $-5.63 \%$ & -8831 \\
\hline Transportation & 918 & 2093 & $-56.14 \%$ & -1175 \\
\hline Undeveloped/rural & 72517 & 58547 & $+23.86 \%$ & +13970 \\
\hline
\end{tabular}

fragmented in its spatial structure over that 5 -year period, although fragmentation stabilized between 1995 and 2000.

The decrease in residential patches was particularly dramatic. 8,831 patches of single-family housing were lost in the 5 years between 1995 and 2000. (This is a large number, but the threshold for patch analysis was set to $100 \mathrm{~m}$, which catches the geography of small patterns.) This suggests a growth in large-swath single-family housing, i.e. large sub-divisions. As shown in Fig. 2, much of this new single-family was added to Austin's ambient suburbs and fringe between 1990 and 2000. The suburbs are clearly expanding and consolidating in large-tract single-family patterns. At the same time, the city appears to be filling-in remaining open space and rural patches as part of this consolidation. Figures 5, 6, 7, 8 and 9 show that accessibility to amenities is relatively abundant, which might explain why this regime "works".

The results of fractal analyses showed an overall reduction in the fractal dimension (by -0.017 from 1990 to 2000) for the city (Table 8). This suggests that the city performed a poorer job of filling space, successively, over that period and indicates overall regional fragmentation in its spatial structure. The results per land-use show that all uses except office, open space, and undeveloped/rural increased their fractal dimension from 1990 to 2000. Multi-family uses, in particular, showed a growth in their space-filling ability as measured by fractal dimension $(+0.221$ from 1990 to 2000; Table 9). This suggests that dense housing is tending to grow more compact.

Our analyses of the uses of urban space suggest a tendency toward more mixed use from 1990 to 1995 , followed by a period of separation of uses from 1995 to 2000. The contagion index for the city dropped by more than $10 \%$ from 1990 to 1995, although the trend reversed slightly from 1995 to 2000 (Table 8). This

Table 8 City-wide metrics

\begin{tabular}{lllllll}
\hline Year & Number of patches & PAFRAC & Contagion & IJI & SHDI & SIEI \\
\hline 1990 & 14,702 & 1.230 & 80.780 & 57.987 & 0.923 & 0.402 \\
1995 & 20,775 & 1.215 & 70.231 & 58.719 & 1.441 & 0.719 \\
2000 & 20,405 & 1.213 & 71.369 & 61.190 & 1.340 & 0.574 \\
Change 1990 to 2000 & 5,703 & -0.017 & -9.411 & 3.203 & 0.417 & 0.172 \\
\hline
\end{tabular}


Table 9 Fractal dimension, by land-use

\begin{tabular}{lllll}
\hline Land-use & 2000 & 1995 & 1990 & Change, 1990 to 2000 \\
\hline Civic & 1.222 & 1.229 & 1.222 & Negligible \\
Commercial & 1.322 & 1.268 & 1.264 & 0.058 \\
Industrial & 1.243 & 1.241 & 1.233 & 0.010 \\
Large-lot single-family & 1.225 & 1.209 & $\mathrm{NA}$ & $\mathrm{NA}$ \\
Mining & 1.216 & 1.217 & 1.214 & 0.002 \\
Mobile homes & 1.250 & 1.260 & 1.250 & 0.000 \\
Multi-family & 1.472 & 1.267 & 1.251 & 0.221 \\
Office & 1.253 & 1.252 & 1.295 & -0.042 \\
Open space & 1.241 & 1.245 & 1.253 & -0.012 \\
Single-family & 1.314 & 1.301 & 1.246 & 0.068 \\
Transportation & 1.339 & 1.433 & 1.284 & 0.055 \\
Undeveloped/rural & 1.231 & 1.226 & 1.296 & -0.064 \\
\hline
\end{tabular}

suggests that the city became 10\% more fragmented from 1990 to 1995 (recall that contagion reaches $0 \%$ when there is maximum fragmentation of pixels in the landscape). The interspersion and juxtaposition index (IJI) grew by over 3\% from 1990 to 2000, which demonstrates that there was a slight reduction in fragmentation of patches. We know from our analysis of patch dynamics that the number of patches increased, which explains growth in the IJI.

The results for diversity and evenness also support a diagnosis of increased fragmentation for the city. There was a steady increase in value of Shannon's Diversity Index (SHDI) from 1990 to 2000. Recall that SHDI reaches zero when diversity (in land-use mix) is absent. The SHDI increased by 0.417 from 1990 to 2000, suggesting increased land-use mix (Table 8). The results for Simpson's Evenness Index (SIEI) also showed an increase, of 0.172 from 1990 to 2000 (Table 8). The value of SIEI nears zero when the landscape becomes dominated by a single patch of activity. The increase in SIEI points to a growing unevenness in the geography of the city's patch distribution. Again, this suggests increased fragmentation in the city's spatial structure. The finding that land-use became more mixed in the face of sprawl runs counter to much of the sprawl literature, which suggests that sprawl causes land-use isolation and spatial homogeneity, particularly in large-lot residential uses (Benfield et al. 1999; Ewing 1994, 1997).

\section{Conclusions}

The need for a rugged methodology for diagnosing sprawl across its multidimensional characteristics is strong. We have presented a novel approach to sprawl analysis in this paper that is robust to characterization and well-known barriers to analysis. The toolkit proves to be useful in examining our study area, allowing us to sweep sprawl's parameter-space over an entire urban area (both regionally and locally), and to capture its space-time dynamics. It offers unique opportunities to glimpse under the hood of Austin's growth machine, and check the sprawling pulse of the city. The fruits of that analysis are significant. First, it allows us to evaluate, empirically, much of the debate in the theoretical literature. Second, it suggests some 
important factors in exploring and studying sprawl. Third, it provides a quantitative basis for evaluating smart growth efforts in the city.

The characterization of sprawl in urban studies literature was discussed in "Introduction". What, if anything, does our analysis have to offer to that debate? Urbanization and urban growth act as the engine for sprawl. Planning and managing growth can clearly help in controlling or at least influencing sprawl. Much of Austin's new urbanization and a large amount of its growth occurred outside the boundaries of the city, likely because it is relatively unchecked in those areas in comparison to growth in the central city.

Social characteristics are also important in understanding sprawl. Austin does appear to exhibit a level of social polarization (at least based on residential tenure). Further work is needed to assess whether this is associated with white flight, inequitable distribution of wealth, or Social justice issue. Density is also a good beacon for sprawl in Austin. In our case study, measurement of net and gross density pointed to relative sprawl in the same places and at the same times. The same can be said for measurement of developed and developable land. Scatter and fragmentation are also appropriate measures of sprawl. We did find, however, that fragmentation was associated with land-use mix, which counters popular theory. Decentralization is a more intricate index of sprawl. Austin showed evidence of decentralization in some places but not others. A characteristic doughnut-hole effect of decentralization on the urban core was not evident. Indeed, the city decentralized considerably but not at the expense of the core. The central city actually stands as a landmark to compact smart growth. Jobs have not fled to the suburbs, which seems counter to trends reported by the Federal government for other cities (OTA 1995).

Accessibility is the most problematic index of sprawl. Superficially, the role of accessibility seems diluted as key amenities can be reached almost ubiquitously, regionally, across the city, and locally. The $\mathrm{CBD}$ is accessible city-wide, as are important urban amenities: employment, schools, and other educational opportunities. Jobs do not seem to have abandoned the central city to follow population to the periphery; there seems to be little need to do so. Omnipresent accessibility facilitates a massive and thriving band of sprawl on the outskirts of the city because it provides access to a strong central core, concurrently eroding some of the motivation for living close to a central city at high densities. Accessibility of this nature is strongly auto-oriented, however, which raises questions of social justice if we consider those sections of the population that may not have access to automobiles. It also raises questions of environmental sustainability.

Our findings also point to some significant considerations in studying sprawl. The lens through which sprawl is characterized is clearly important. Our analysis suggests that the current debate in the literature is a healthy one: all of the characteristics of sprawl are relevant and all are needed to diagnose sprawl. Further work may be needed to explore whether one characteristic or another can be tied to costs and benefits with greater or lesser degree, but deriving empirical metrics that match to well-discussed characteristics is a positive step in that endeavor.

Geography is clearly important in diagnosing sprawl. Our analysis focused on a single city, but it could be applied to several cities, to look at the geography of sprawl in different regions or among systems of cities. The internal geography of a city is very significant. Sprawl conditions in Austin vary remarkably on an intraSpringer 
urban basis. Austin hosts geographically distinct zones of sprawl and compaction (with footprints that are evident across characteristics) rather than housing a slippery slope toward sprawl with a regular gradient. Each of the characteristics of sprawl paints a different picture of the phenomenon. At least in Austin, however, those characteristics point to sprawl in the same places.

Sprawl, it would appear, is a matter of scale. Different spatial resolutions of analysis yield different results when testing for sprawl. Globally, looking at Austin as a single city, it is debatable as to whether the city sprawls at all. Locally, however, the city is seen to sprawl classically in some areas, while others stand as a monument to the compact city. This explains the diversity of opinion regarding the city in other studies; the compact central core and surrounding band of sprawl cancel each other out when considered globally. The work presented here is not intended to be prescriptive or normative in any way, but it does hint at some planning and policy issues, suggesting, at least, that growth management should be local and intra-urban. Scale should be a factor in managing sprawl.

Dynamics are clearly important. It is essential to look at the trajectory of a city across a range of characteristics when examining sprawl. Urbanization is Markovian: patterns evident today are a legacy of development in times past. Considered dynamically, Austin appears to have developed under successive waves of urbanization. The city's original compact core has been joined (but not supplanted) by a second urbanization on the periphery, and these structures are still forming in space and time. Over 10 years, both seem to be (co-) evolving in their geography, but they are quite different systems, with different - but not necessarily mutuallyexclusive - trajectories. A peripheral sea of sprawling suburbanization has steadily formed in outer Austin, and it is extending its spatial footprint at an increasing rate. Concurrently, the central city has coalesced around an anti-sprawl core, which is slowly extending outward and upward. This has not been enough to combat sprawl. Rather than filling-in over time, Austin appears to be growing more fragmented and homogeneous in land-use activity, reversing a trend toward less fragmented and mixed-use in the early-1990s. Austin, unlike Portland (Song and Knaap 2004), may be losing the battle against sprawl in some places, while winning elsewhere.

What, if anything, does our analysis tell us about the efficacy of Austin's growth management policies? Details of the growth management strategy for the city are discussed in Sui et al. (2004). The city has targeted the central city as a zone of growth management, which explains why that area appears as an antithesis of sprawl in our study. Moreover, the City of Austin has embarked upon a scheme to increase city-wide accessibility, which again explains why accessibility was found to be so ubiquitous in the urban area. Areas outside their urban growth boundaries correspond to those areas found to be prone to sprawl in our study.

Our findings also point to the potential benefit of promoting edge cities as a binding mechanism amid large swaths of suburban sprawl. This is a thesis supported, in some part, by planners at the University of Southern California (Gordon and Richardson 1997a, b; Peiser 1989). Los Angeles is a clear example of an urban area that presents with many of the characteristics of sprawl, but also seems to be quite compact in its spatial structure (Gordon and Richardson 1997b). This may also be true of Austin.

Ewing, Gordon, and Richardson sparked a debate in the literature in the late1990s about what planners should aspire to as goals in managing sprawl. Ewing 
(1997) criticized Los Angeles as an archetype of relatively unmanaged sprawl, while Gordon and Richardson (1997a, b) defended the city, putting forward a convincing argument as to why Los Angeles should actually be considered as quite compact. To the extent that Austin appears to be managing sprawl successfully in its central city, perhaps Austin-style (and Los Angeles style, by extension) sprawl is the desirable planning goal. The idea of using edge cities to reign-in sprawl has also been suggested in recent work in simulating the phenomenon (Torrens 2006) and this would seem to lend further weight to the thesis.

Considered together, our results suggest that the best way to measure sprawl may be by means of differential diagnosis. All of a city's sprawl symptoms should be evaluated, with further investigation to consider which present as the most likely drivers of the phenomenon and where co-dependencies exist. In the case of Austin, the city plays host to a wide band of low-density housing because accessibility is almost ubiquitous to those residents with access to cars and gas to fuel them. This low-density scattered mass is decentralizing, and rapidly so, because it is anchored by a resiliently compact central core that is accessible. Use of urban space within and outside this core appears to offer most essential urban activities. The core and periphery of the city are clearly of equal importance in examining and explaining sprawl. The geographical arrangement in Austin is of a strong central city served by (and serving) a satellite band of sprawl. This is an arrangement that seems to work. Whether it is sustainable, or works efficiently, socially, or environmentally is debatable. There are different arrangements in other cities: ubiquitous sprawl punctuated by polynucleated centers that bind the urban mass; tri-structural forms of downtown, suburb, and edge city; and quad-structural forms with an extra ring of exurban settlement. More work is needed to explore whether Austin is the exception or the norm.

Our findings, and the theses that we have just offered, raise questions, however, as to whether the relationship between sprawl and compact development is symbiotic, parasitic, or simply a mutual tolerance? It also raises the issue of how we might theorize, plan, and manage cities for both sprawl and smart growth? Moreover, it begs the question as to what we consider to be desirable urban forms decentralization without end (Hall 1983), Los Angeles-style sprawl (Ewing 1997), compact cities (Gordon and Richardson 1997a), some historical urban form of great times gone-by (Jacobs 1961), a revived but New Urbanism (Katz 1993), an edge city frontier (Garreau 1992), or an alternative urban morphology (Calthorpe et al. 2001; Duany et al. 2000; Duany et al. 2001)? These are all questions that are better debated in policy and practice. Nevertheless, answering these questions - or at least debating them on common terms - will require empirical tools.

\section{References}

Alberti, M. (1999). Modeling the urban ecosystem: A conceptual framework. Environment and Planning $B, 26(4), 605-630$.

Anselin, L. (1995). Local Indicators of Spatial Association - LISA. Geographical Analysis, 27(2), $93-115$.

Audirac, I., Shermyen, A. H., \& Smith, M. T. (1990). Ideal urban form and visions of the good life: Florida's growth management dilemma. Journal of the American Planning Association, 56(4), 470-482.

Bae, C.-H. C., \& Richardson, H. W. (1994). Automobiles, the environment and metropolitan spatial structure. Cambridge, MA: Lincoln Institute of Land Policy. 
Benfield, F. K., Raimi, M. D., \& Chen, D. D. T. (1999). Once there were Greenfields: How urban sprawl is undermining America's environment, economy, and social fabric. New York and Washington, DC: Natural Resources Defense Council.

Berry, W. D. (1993). Understanding regression assumptions. Newbury Park, CA: Sage.

Burchell, R. W., Shad, N. A., Lisotkin, D., Phillips, H., Downs, A., Seskin, S., et al (1998). The costs of sprawl revisited. Washington, DC: National Academy Press.

Burchfield, M., Overman, H. G., Puga, D., \& Turner, M. (2006). Causes of sprawl: A portrait from space. The Quarterly Journal of Economics, 121(2), 587-633.

Calthorpe, P., Fulton, W., \& Fishman, R. (2001). The regional city: Planning for the end of sprawl. Washington, DC: Island Press.

Clapham, W. B., Jr. (2003). Continuum-based classification of remotely sensed imagery to describe urban sprawl on the watershed scale. Remote Sensing of Environment, 86, 322-340.

Duany, A., Plater-Zyberk, E., \& Speck, J. (2000). Suburban nation: The rise of sprawl and the decline of the American dream. New York: North Point Press.

Duany, A., Speck, J., \& Plater-Zyberk, E. (2001). Smart growth: New urbanism in American communities. New York: McGraw-Hill.

El Nasser, H., \& Overberg, P. (2001). A comprehensive look at sprawl in America. USA Today, February 22.

Ewing, R. (1994). Causes, characteristics, and effects of sprawl: A literature review. Environmental and Urban Issues, 21(2), 1-15.

Ewing, R. (1997). Is Los Angeles-style sprawl desirable? Journal of the American Planning Association, 63(1), 107-126.

Ewing, R., Pendall, R., \& Chen, D. D. T. (2002). Measuring sprawl and its impact. Washington D.C.: Smart Growth America

Farley, R., \& Frey, W. H. (1994). Changes in the segregation of whites from blacks in the 1980s: Small steps toward a more integrated society. American Sociological Review, 59, 23-45.

Forman, R. T. T. (1995). Land mosaics: The ecology of landscapes and regions. Cambridge: Cambridge University Press.

Fotheringham, A. S., Brunsdon, C., \& Charlton, M. (2000). Quantitative geography: Perspectives on spatial data analysis. London: Sage.

Fotheringham, A. S., Brunsdon, C., \& Charlton, M. (2004). Geographically weighted regression: The analysis of spatially varying relationships. Chichester: Wiley.

Fulton, W., Pendall, R., Nguyen, M., \& Harrison, A. (2001). Who sprawls most? How growth patterns differ across the U.S. Washington, DC: The Brookings Institution.

Galster, G. (1991). Black suburbanization: Has it changed the relative location of the races?. Urban Affairs Quarterly, 26, 621-628.

Galster, G., Hanson, R., Ratcliffe, M. R., Wolman, H., Coleman, S., \& Freihage, J. (2001). Wrestling sprawl to the ground: Defining and measuring an elusive conceptHousing Policy Debate, 12(4), 681-717.

Garreau, J. (1992). Edge city: Life on the new frontier. New York: Anchor Books/Doubleday.

Getis, A., \& Ord, J. K. (1992). The analysis of spatial association by use of distance statistics. Geographical Analysis, 24(3), 189-207.

Giuliano, G. (1989). New directions for understanding transportation and land use. Environment and Planning A, 21, 145-159.

Gordon, P., \& Richardson, H. W. (1997a). Are compact cities a desirable planning goal? Journal of the American Planning Association, 63(1), 95-106.

Gordon, P., \& Richardson, H. W. (1997b). Where's the sprawl? Journal of the American Planning Association, 63(2), 275-278.

Hall, P. (1983). Decentralization without end? In the expanding city: Essays in HONOR OF PROFESSOR Jean Gottmann. London: Academic.

Hasse, J. (2004). A geospatial approach to measuring new development tracts for characteristics of sprawl. Landscape Journal, 23(1), 52-67.

Hasse, J., \& Lathrop, R. G. (2003a). A housing-unit-level approach to characterizing residential sprawl. Photogrammetric Engineering and Remote Sensing, 69(9), 1021-1030.

Hasse, J. E., \& Lathrop, R. G. (2003b). Land resource impact indicators of urban sprawl. Applied Geography, 23, 159-175.

HUD. (1999). The State of the Cities. Washington, DC: US Departmet of Housing and Urban Development.

Jacobs, J. (1961). The death and life of great American cities. New York: Random House. 
James Duncan \& Associates, Van Horn, G. A., Ivey, B., Harris, and Walls, Inc., \& Wade-Trim, I. (1989). The search for efficient urban growth patterns: A study of the fiscal impacts of development in Florida. Presented to the Governor's Task Force on Urban Growth Patterns and the Florida Department of Community Affairs, July 1989.

Katz, P. (1993). The new urbanism: Toward an architecture of community. New York: McGraw-Hill.

Krummel, J. R., Gardner, R. H., Sugihara, G., \& O’Neill, R. V. (1981). Landscape patterns in a disturbed environmentOikos, 48, 321-324.

Lang, R. E. (2003). Open spaces, bounded places: Does the American West's arid landscape yield dense metropolitan growth? Housing Policy Debate, 13(4), 755-778.

Ledermann, R. C. (1967). The city as a place to live. In J. Gottmann, R. A. Harpe (Eds./), Metropolis on the move: Geographers look at urban sprawl. New York: Wiley.

Lessinger, J. (1962). The cause for scatteration: Some reflections on the National Capitol Region plan for the year 2000. Journal of the American Institute of Planners, 28(3), 159-170.

Lopez, R., \& Hynes, H. P. (2003). Sprawl in the 1990s: Measurement, distribution, and trends. Urban Affairs Review, 38(3), 325-355.

Malpezzi, S. (1999). Estimates of the measurement and determinants of urban sprawl in U.S. mteopolitan areas. Madison, WI: University of Wisconsin, Center for Urban Land Economics Research.

Mills, E. S., \& Tan, J. P. (1980). A comparison of urban population density functions in developed and developing countries. Urban Studies, 17, 313-321.

Moran, P. A. P. (1950). Notes on continuous stochastic phenomena 37. Biometrika, 37, 17-23.

Openshaw, S. (1983). The modifiable areal unit problem, CATMOG 38. Norwich: GeoBooks.

OTA. (1995). The technological reshaping of Metropolitan America. Washington, DCUS Congress Office of Technology Assessment.

Peiser, R. (1989). Density and urban sprawl. Land Economics, 65(3), 193-204.

Pendall, R. (1999). Do land-use controls cause sprawl? Environment and Planning B, 26, 555-571.

Real Estate Research Corporation (1974). The costs of sprawl: Environmental and economic costs of alternative residential patterns at the Urban Fringe. Washington, DC: US Government Printing Office.

Riitters, K. H., O’Neill, R. V., Wickham, J. D., \& Jones, K. B. (1996). A note on contagion indices for landscape analysis. Landscape Ecology, 11(4), 197-202.

Shannon, C. E. (1948). A mathematical theory of communication. Bell System Technical Journal, 27, 379-423, 623-656.

Sierra Club. (1998). Sprawl: The dark side of the American dream. College Park, MD: Challenge to Sprawl Campaign.

Song, Y., \& Knaap, G.-J. (2004). Measuring urban form: Is Portland winning the war on sprawl? Journal of the American Planning Association, 70(2), 210-225.

Sudhira, H. S., Ramachandra, T. V., \& Jagadish, K. S. (2003). Urban sprawl pattern recognition and modeling using GIS. Paper read at Map India Conference 2003.

Sui, D. Z., Wei, T., \& Gavinha, J. (2004). How smart is smart growth? The case of Austin, Texas. In D. G. Janelle, B. Warf, K. Hansen (Eds.), World Minds: Geographical perspectives on 100 problems (pp. 209-214). Dordrecht: Kluwer.

Sultana, S., \& Weber, J. (2007). Journey-to-work patterns in the age of sprawl: Evidence from two midsize southern Metropolitan Areas. The Professional Geographer, 59(2), 193-208.

Torrens, P. M. (2006). Simulating sprawl. Annals of the Association of American Geographers, 96(2), $248-275$.

Wong, D. W. S., \& Lee, J. (2005). Statistical analysis of geographic information. Hoboken, NJ: Wiley. 